\title{
Multiple identities in the Beaker period: interpreting inhumations out of the Beaker spotlight in southern England
}

\begin{abstract}
The Beaker period in southern England is associated with the appearance of a highly visible set of material culture in the archaeological record, primarily associated with inhumation burials. This Beaker material culture has a long history of archaeological research and has resulted in this period being named after a style of pottery, the Beaker. However, the funerary record for this period is one that exhibits substantial variability. This paper considers how the archaeological narrative of the Beaker period has been constructed and presents a set of examples that exclude Beaker pottery and Beaker artefacts from the grave assemblage, located in southern England. Herein, it is questioned what these burials represent and whether they can be considered Beaker burials or represent other identities co-existing with Beaker using societies. Whilst the Beaker period does not represent an unchanging, fixed set of traditions over time or space, the examples employed demonstrate non-Beaker related burials to have been present from early in the Beaker period. We aim to highlight this important aspect of the archaeological record as requiring more research and synthesis, and promote discussion of non-Beaker identities during this dynamic period of prehistory.
\end{abstract}

Keywords: Beaker period, identity, inhumation, Beaker pottery

\section{Introduction}

Since Thomsen developed a three age system of stone, bronze and iron (RowleyConwy, 2004), archaeological investigation has utilised chronological ages to denote periods of archaeological continuity and change. The utilisation of chronological ages reached a zenith when they were bound up with the notion of archaeological cultures, across both time and also space (Childe 1925). The processual revolution of the 1960s criticised culture history as an inadequate framework for interpreting the past (Johnson 2010), and although the notion of distinct and unified archaeological cultures fell out of 
use, the application of conventional time periods remain within the archaeological literature. Whilst many archaeologists have argued against the sensibility of using distinct archaeological periods to dissociate periods of time (e.g. Piggott 1954, xv, in reference to the Neolithic), owing to the underlying implication of social, technological and cultural/ideological homogeneity, the use of these terms has persisted; this is significant as the use of such chronological separators implies a sequence of monoideological views of the past, especially in relation to prehistory.

The arrival of the Beaker complex in southern England is an example where a time period is bound up with the notion of an archaeological culture; the Beaker period. However, this period also presents an opportunity to investigate the notion of ideological variation in the past and to question the funerary record of this time period, as one that could contain multiple identities. The date of the Beaker using phase in Britain is from 2450BC through to a very late phase up to $c$. 1650BC (Needham 2005), although significant regional variation exists in adoption and longevity of Beaker style burials (for example see Jones and Quinnell 2006).

Within southern England, Beaker burials have been the subject of sustained research, particularly in Wessex, starting with the work of early Antiquaries e.g. Colt Hoare (1812), through to more recent discoveries such as the Amesbury Archer (Fitzpatrick 2013). There have been multiple typological schemes applied to Beaker pots in Wiltshire (e.g. Case 1995b) as well as more broadly (e.g. Clarke 1970; Needham 2005), focusing on various decorative and shape categorisations. As a consequence of this long history of research the period is named after the type of pottery associated with it, the Beaker (e.g. Boast 1995, 69), and although variation in the archaeological record not associated with Beaker pottery is noted during this time period, Beaker burials still dominate the archaeological narrative (e.g. Cummings 2017, chapter 9). Is it questionable that this 'Beaker period' has been over-stated within the archaeological literature and is it possible that the arrival, adoption and use of the Beaker package in southern England is one of multiple identities in existence during this time period?

This theme, whilst not yet explored in detail in southern England, has been investigated in northern Britain and Scotland, where burials associated with Food Vessels and Beaker pots chronologically overlap and initially occupy separate areas (Wilkin 2011; Shepard 2012). However, the Food Vessel funerary record of southern England is less numerous and is not spatially distinct, with Beaker burials seemingly dominating the 
funerary record of this time (e.g. Field and Mcormish 2017; Bowden et al. 2017). Unquestionably, the arrival and adoption of the Beaker set in southern England is a highly visible and significant archaeological phenomena, but behind this archaeological spotlight are other burial practices and identities evident?

In order to consider this question, this paper considers how the Beaker period has been defined, before a summary of approaches to interpreting the Beaker period and the wider context of the funerary landscape at this time. From this, the paper discusses the possibility of interpreting burials practices that are not aligned with the Beaker complex, through a series of case studies of burials in southern Britain, which are questioned as being non-Beaker in identity. This contribution attempts to promote more discussion into how non-Beaker identities might be interpreted and highlight this area for future research.

\section{Defining the Beaker period}

The British Chalcolithic has recently been the subject of debate (see Allen, et al. (eds) 2005), with discussion of including the term Chalcolithic within the archaeological narrative for the British Isles, to define a distinct copper using phase, 2450-2250BC, which is synchronous with the adoption of Beaker material culture. Needham (2005) provides a clear chronological framework for the adoption and use of Beaker material culture within the UK, and this framework is adopted in this contribution. Within this model there is an initial circumscribed exclusive Beaker culture between 2450-2250BC. This early phase utilises a rather limited number of artefact associations in funerary deposits and coexists alongside native Later Neolithic tradition/s. This is followed by a fission horizon, at c. 2250BC. After this fission horizon the Beaker culture in Britain is an instituted culture (2250-1950BC), witnessing a diversification of Beaker pottery types and artefact associations. In the instituted culture phase, Beaker culture is no longer a select identity, but becomes mainstream, and as a consequence of this the need to maintain an identity in relation to the 'other' has seemingly reduced, allowing diversification of Beaker cultural traditions. The meanings of Beaker culture change and evolve, and new styles of pottery start to be used (e.g. Food Vessels and Collared Urns), and in some cases Beaker pottery starts to be excluded from grave assemblages. Finally, there is a Beaker as past reference phase (1950-1650BC) that typically produces poorly furnished graves, 
possibly of a minority of society who seemingly associate themselves with a Beaker ancestry, with a variety of other burial practices evident at this time (see below).

This is a useful way of framing the ingression and subsequent adoption of the highly visible Beaker material culture into the British prehistoric social landscape. Recent research has identified several early Beaker burials as isotopic aliens, pioneers that transported with them the early Beaker package into the UK (Needham 2007; Sheridan 2012). The Beaker People Project has shown that whilst there is some mobility in the Beaker period, a relatively low number of early pioneers (isotopic aliens) arrived into the UK from the continent (Parker Pearson et al. 2016). Whilst it is clear that the Beaker 'idea' was adopted and then later diversified within Britain, there has been relatively little consideration of the social landscape outside of the Beaker culture during this period within southern England.

\section{Approaches to analysing Beaker period funerary practices}

The archaeological narrative of the Beaker period in southern England has been primarily constructed from the excavation and interpretation of inhumation burials. This analysis and interpretation of the Beaker funerary record has been influenced by changes in archaeological theory. As a crude dissection, there are three key stances of archaeological thought that have strongly influenced the narrative of this period (Wilkin 2011). These can be summarised as culture history from $c .1910-1965$, processual systems theory from $c .1965-1985$ and then post processual frameworks from $c .1985$ onwards (dates from Darvill 2010, 13).

Each of these interpretative stances brought a different perspective and process to analysing and interpreting the funerary record of the Beaker period. Culture history related assemblages of material culture to groups of people, often defined by ethnicity or race (Johnson 2010). The use of culture historical models was inherently bound up with ideas of invasion causing the spread of material culture typified by the often quoted (Hawkes and Hawkes, 1949) invasion of Britain by the Beaker folk. Whilst various versions of the culture history model of the Beaker infiltration into Britain were proposed, the inference was that the Beaker people came to Britain and attained some form of ascendancy over native populations. 
The processual revolution of the mid to late 1960s in some ways had a dramatic impact on the interpretation of the Beaker period, primarily through the work of Clarke (1970) who applied statistical modelling (matrix analysis) of measurements of Beaker pots, to create a new typo-chronological scheme for the uptake and use of Beaker pottery in the UK. Clarke's model did define regional groupings and a suggested chronology of Beaker pottery, with the new typo-chronological sequence used to explain in more detail the sequence of the spread of Beaker people across Britain and regional variation in Beaker pottery styles.

Towards the end of the processual period and at the start of the post processual movement, the interpretation of Beaker burials focused on the rise of the individual, indicating a shift from a group centred to ego centred society, with certain individuals having access to prestige goods and resources (Thomas 1991, 34). Post processual approaches diversified and developed a range of interpretations of Beaker funerary traditions, utilising explanations such as creation of memory and myth, and the construction of identity through relational aspects of people and objects (e.g. Brück 2004), which in some studies has been applied to burial styles over a regional scale (e.g. Fowler 2013). Within post processual interpretations, the standard models of acquired status through prestige goods were replaced with relational consideration of material assemblages, and how grave assemblages reflect the social identity, connections and relationships of the deceased. Some recent work on interpreting Beaker period funerary assemblages has adopted a more contextual approach (Wilkin 2011; 2013), creating a balanced and closer relationship between interpretation and data collection, using a regional perspective.

Each approach has provided new insights into the reasons for the diversity and differences within the funerary record of the Beaker record. Using the adoption of these different interpretative lenses significant questions are contested. Why was there such diversity of funerary practice at this time? Why do the grave assemblages contain pottery styles that are current over wide geographic spreads? Does the presence of Beaker material culture in the archaeological record represent a distinct social identity or belief system? What was the reaction of the indigenous population to the arrival of these new symbols and items? And, can we equate Beaker pottery and material with specific groups of people? To question the perspective of non-Beaker identities during this period, it is now necessary to consider the funerary landscape of the period in southern England. 


\section{Funerary context and the Beaker package}

The funerary record from the Beaker period contains significant variation, with inhumations occurring in flat graves, and under and within barrows. There is a spectrum of inhumation practices, with some well-furnished graves such as the Amesbury Archer (Fitzpatrick 2013) through to single inhumations with only a Beaker pot, e.g. the Sanctuary burial, Avebury, (Cunnington 1931). Using the chronological framework described above, the initial exclusive phase witnessed a low number of burials associated with a limited artefact range. Although some of these early burials displayed large numbers of artefacts, the variety of artefacts is still limited (Needham 2005; Sheridan 2012), with early copper knives, Beaker pots, barbed and tanged arrowheads, stone wrist guards and occasional gold hair ties (ear rings) present. Healey (2012) highlights the paucity of evidence for a tradition of inhumation in the British Isles, prior to the adoption of this Beaker burial style, strongly indicating that Beaker inhumations were an intrusive element, rather than an adaption of a pre-existing burial custom. Following the fission horizon there is a diversification of Beaker pottery types in the instituted phase (22501950BC), with an increasing array of funerary grave goods, including jet buttons, pulley rings, boars tusks, battle axes, whet stones, bronze knives/daggers, barbed and tanged arrowheads and flint daggers, as some of the more common types (Case 2004a).

However, these grave goods occur in varying proportions in different inhumations and are often not present. It is unclear what social rules governed the inclusion of these different grave goods within burials, although commonly argued stances are social status (e.g. Case 1995a; Brodie 1997), and relational aspects between the deceased and the societies and the landscapes that they lived within (Brück 2004; Fowler 2013). Grave goods are often exotic items, utilising raw materials that were sourced many miles away from the location of the burial. This has been interpreted to indicate extensive exchange routes as a feature of the Beaker culture across Europe, and part of the identity of being Beaker (Needham 2007). In contrast, the Beaker pot is normally made from local clays (Gibson 2002; Hamilton 2002, 48) and consequently, Beaker graves can contain a collection of materials, which have been acquired from a range of resources, from local to sometimes international scales. Finally, in the Beaker as past reference phase (1950$1650 \mathrm{BC}$ ) there are poorly furnished graves of a minority in society associating themselves with a Beaker ancestry, often buried with poorly made Beaker pots. 
Beaker burials are not only restricted to single inhumation burials and variability is evident, although single inhumation appears to be the most common rite (Fitzpatrick 2017). The Boscombe Bowmen are an example of a multiple burial of at least 5 adult males, a teenager, and one, possibly two children, and seven Beaker pots (Fitzpatrick 2013). Other examples of multiple burial are Trumpington Meadow, Cambridge, with two individuals buried toe to toe, with a Beaker pot placed close to each head (Patten 2012), and stone hole 25b on the West Kennet Avenue with 3 individuals represented (Smith 1965).

Fitzpatrick (2013, chapter 9) highlights the presence of timber chambers within some early Beaker graves providing access to the contents of the grave, potentially allowing the removal/addition of grave goods and bones, such as the disarticulated and partial skeleton of a female in grave 5225 on Porton Down, (Andrews and Thompson 2016). The revisiting and rearranging of body parts and grave goods is likely to have been a significant component of at least some Beaker burials. Other factors important in the symbology of Beaker burial are body orientation, position of artefacts relative to the body, and the size of the grave cut. Bodies within Beaker graves in southern England are interred on a general north-south axes, indicating some wider aspect of belief or meaning behind orientation of the body in the grave (Shepherd, 2012 274). Thomas (1991) demonstrates a relationship between increasing grave size and the increasing number of artefacts placed in the grave, including more than one Beaker pot, possibly indicating larger graves had more grave furniture included in them. Likewise, the position of artefacts within Beaker graves is important, with common areas for the positioning of items being close to the head, in front of the chest, behind the back and at the feet (Brück 2004). Shepherd (2012) recognises gender preferences for orientation in Beaker burials from East Yorkshire and northeast Scotland. A prevalent east/west axis of body alignment exists in the northern British burials (although variation does exist), which is different to the general north-south axis in southern England, suggesting regional adaptions to the Beaker phenomena.

During this period there was also adoption of different funerary traditions, alongside the Beaker inhumation style. Post the fission horizon and alongside the diversification of grave goods found within Beaker graves, there is adoption of Food Vessel burials initially associated with inhumations, but also subsequently cremations. Food Vessels are more commonly found within Northern Britain, although examples of 
Food Vessel burials do occur in southern England, they are relatively low in number; for example Exon et al. (2000, 82) recorded ten occurrences in the Stonehenge area associated with barrows. The date range for Food Vessel use in Scotland is suggested as between 2140-1980 cal BC and 2020-1865 cal BC (Wilkin 2011), with relatively few dates for Food Vessel burials within southern England, the majority of these burials having been excavated by early Antiquarians. At Bulford, Wiltshire, a cremation burial associated with a miniature Food Vessel is suggested to date between 1900-1750BC by Parker Pearson $(2012,153)$ and another recently excavated example at Porton Down Wiltshire, of an infant with a miniature Food Vessel did not have enough bone material for dating (grave 5116; Anderson and Thompson 2016). In barrow 12 grave 605 at Barrow Hills (Oxfordshire), a Food Vessel accompanied the inhumation of a child dating to 2350-1750 cal BC (2 sigma, OxA-1884) placed above an earlier cremation (Barclay and Halpin 1999, 101).

There was also widespread use of Collared Urns primarily associated with cremation burials in the later phases of the Beaker period across southern England. Wilkin $(2013,52-53)$ from a synthesis of burials in northern Britain provides a start date for the use of Collared Urns in funerary rites, which does do not begin until the end of the 21 st or the start of the 20th century BC. Importantly, there is overlap with the end of the Beaker instituted phase and the Beaker as past reference phase. Grave 9647 from Area 7 of the defence training estate on Salisbury plain contained an inverted Collared Urn over the burial of an infant and provided a date from cremated bone of 2030-1880 cal BC (SUERC - 50593; Powell et al. 2018). Likewise, Garrow et al. (2014) from excavations at Over Cambridgeshire, interpret an overlap between the earliest deposition of Collared Urn cremations and Beaker related inhumations within the Low Grounds cemetery; the earliest burials associated with Collared Urns within barrow 12 were modelled to be c.1900BC, overlapping or pre-dating the last unaccompanied infant inhumations referencing a 'rich' Beaker flat grave. A less common form of pottery also found in funerary contexts in southern England are Accessory Vessels, and although relatively low in number, some have been found with well-furnished burials, such as Preshute G1a (Woodward and Hunter 2015, 448) and the log coffin burial at barrow 4, (G4a) Milton Lilbourne. The associated radiocarbon dates with (G4a) Milton Lilbourne barrow suggest a date for Accessory Vessel use in Wessex post 2000BC (Jones et al. 2017) and this is 
consistent with the set of four dated examples from northern Britain reported by Barrowclough (2010).

Tree-trunk burial is also visible as a distinct burial style during the Beaker instituted phase and Beaker as past reference phase, with a probable start date in the $22^{\text {nd }}$ century BC. In four cases (from sixty five listed), Beaker pottery has been found within tree-trunk burials and nine times tree-trunk burials have been associated with Food Vessels (Parker Pearson et al. 2013). The style of burial occurs across the UK, although there are regional concentrations. One concentration is focused in the Wessex region, with the Wessex examples appearing to have a start date after 2000BC, which is later than in northern Britain (Parker Pearson et al. 2013; Jones et al. 2017). However, Barrow Hills (Oxfordshire) flat grave 950 produced a radiocarbon date of 2290-1960 cal BC (2 sigma; BM2703) and is one of the four examples associated with a Beaker pot, suggesting that some tree-trunk burials could date to the Beaker instituted phase within southern England (2250-1950BC). This style of burial is generally associated with inhumation burial, although cremation is recorded in thirteen cases, with provision of grave goods varying, although some tree-trunk burials contain rare types of grave goods, such as metal daggers (Parker Pearson et al. 2013).

However, within southern England, seemingly the most common form of burial for the Beaker period is a single inhumation accompanied by a Beaker pot, and sometimes other grave goods. Critically, the inclusion of one or more Beaker pots within a grave would not represent an interpretative archaeological problem, if all inhumations from this period did indeed include Beaker pottery. Contrary to Thomas (1991, 34): 'Almost all British Beaker graves contain a Beaker vessel, with the exception of a few late examples', there are burials that do not contain Beaker pottery, pre Needham's (2005) Beakers as past reference phase. In Ancient Wiltshire Colt Hoare (1812) describes many primary inhumations uncovered during the digging of barrows that did not include either grave goods or pottery.

Consequently, such burials do not feature prominently in the descriptions of Ancient Wiltshire, or in later research that utilised this significant archive of excavated material. For example, barrow 51 'two skeletons were found with their heads laid towards the north, one an adult, the other a young person' (Colt Hoare 1829, 26) or barrow 22 'a skeleton' (IBID, 16). It is clear that Colt Hoare and Cunnington (the lead 'excavator') understood the difference between primary and secondary inhumations within barrows: 
"Till within these few years they have been but partially examined, and even then not scientifically. Thomas, Earl of Pembroke, aided by the learned Dr. Stukely, opened a few - but it was reserved for Mr. Cunnington of Heytesbury, to investigate them in a much more perfect manner, and to ascertain, that although sepulchral deposits had been found in the upper part of the tumulus, yet that the primary internment was always placed on the floor of the barrow, and generally within a cist cut into the chalk" (Colt Hoare 1829, B). It is therefore highly likely that some of these primary inhumations recorded by Colt Hoare (1812) that are not associated with grave goods date from the Beaker period.

Needham (2005), using the associations of Beaker grave assemblages, separates Beaker burials into three phases (described above). The junction of the exclusive and instituted (emergent) packages is focused on three significant and unusual funerary groups: Irthlingborough 1, Gravelly Guy and Rudstone 68, although the Rudstone 68 funerary assemblage does not contain a Beaker pot (Greenwell 1887, 262-269). Case (2004a) also recognises distinct variation in Beaker funerary practice and lists five types of 'Beaker' burials; his group 5 are burials including men, women and children forming part of the Beaker set of burials without Beaker pottery.

So whilst a Beaker burial styles has often been discussed, it is clear that examples of inhumations exist from this time period that do not contain Beaker pottery. It is highly likely that many inhumations from the Beaker period have been more recently excavated without any form of grave goods, but given their lack of grave good assemblages have not been radiocarbon dated or further investigated (Gibson 2004; 2007) and as such are under-represented in the archaeological literature. It is also apparent that as well as inhumations without grave goods, some people were interred with extensive numbers of grave goods or highly valued grave goods, but without a Beaker pottery vessel.

It is these inhumations that do not contain a Beaker pot in the grave assemblage that are discussed in this paper. The question, therefore, of what a Beaker pot in a grave assemblage represents, becomes critical. Can an individual who is buried without a Beaker pot, still be considered an individual who was referencing a Beaker identity? This might be considered a circular argument, i.e. a grave without a Beaker pot is not a Beaker grave, but can it be interpreted that this non-inclusion of a Beaker pot was in fact very significant? As Pollard $(2002,28)$ notes: 'The fact that pottery occurs in Earlier Bronze Age burials with such frequency is so readily accepted that we rarely ask why this should be so.' 


\section{Beaker Pots: Purpose and identity}

Needham's $(2005,210)$ chronology for the Beaker period describes: '....at least three definable phases of quite different character and, moreover, with different relationships to the contemporary 'non-Beaker' culture'. It is this non-Beaker culture that forms the focus of the examples below, but what is meant by non-Beaker culture? Or as importantly, what is meant by Beaker culture? Fitzpatrick $(2013,193)$ provides a summary of the reasons previously sought to explain the Bell Beaker package and describes three models of (i) ethnicity and immigration; (ii) status and ranked societies, and (iii) belief systems. He acknowledges that these three categories are not mutually exclusive, but concludes that none of these ideas are convincing enough to explain a panEuropean distribution. However, the fact that the Bell Beaker set does have a pan European distribution, indicates that the Beaker pot did have a symbolic significance, even if the exact meanings/symbolism changed over time and space.

The argument for Beaker pots representing drinking vessels (e.g. Burgess and Shennan 1976, 310-311; Sherratt 1991) is questioned by Case (1995a). More recent analyses have shown some Beakers from funerary assemblages to have been used in cooking, primarily associated with animal fats (Šoberl 2011), although Guerra-Doce (2006) infers a variety of uses for Beakers including drinking, as cremation receptacles and also copper smelting, with all of these activities associated with the process of transformation. Case (2004b) interprets the Beaker pot, and the associated grave goods (stone wrist guards, barbed and tanged arrowheads, and copper alloy knives) as symbolic hunting equipment. The problem with such an interpretation is that it does not explain why such symbolic hunting equipment became so popular over so much of Europe, or why many inhumations contain only Beaker pots with no other grave goods.

Thomas (1991) recognises the grave assemblage as referring to activities which are structuring agencies in society, with the Beaker pot specifically referencing the preparation and consumption of food and drink. Brodie (1997), whilst acknowledging that Beaker pottery in graves cuts across all dimensions of social stratification, interprets the Beaker pots as produced by, and representing, the female (domestic sphere) in burial ritual within a male dominated society. Needham (2007, 44), interprets the Beaker package as: 'The burials featuring this package, or at least part of it, represent individuals entitled to exceptional burials, due to their role as exceptional communicators with the otherworld'. In this case the otherworld refers to non-Beaker areas, and hence such an 
interpretation is understandable in the pioneering phases of Beaker movement into new areas, but is more problematic with continued use and rising popularity of the Beaker pottery style, unless other identities are visible. Fokkens (2008) interprets the selection of Beaker artefacts in burials to represent the consciously constructed identities of exemplary ancestors, with men represented as archers and warriors, in some ways referencing an ideal or image of the Beaker identity.

Needham $(2005,209)$ describes the Beaker culture as one of an initial circumscribed exclusive culture, before becoming an instituted culture post 2250BC, explicitly defining the Beaker package as representing a cultural identity. Resulting from an analysis of Beaker pot size and grave good assemblages, Case (1995a, 63) suggests in reference to the Beaker pot: 'These plainly had symbolic significance, perhaps simply to assert identity in another world'. Both these interpretations for the incorporation of Beaker pottery in the grave move toward an association with cultural identity. Boast (2002) notes regional variations in Beaker style and decoration in the UK, but argues against using variation for the identification of regional (cultural) groupings.

The forms of the Beaker pots selected for grave assemblages reflected those used in life, although the quality of the fabric is often lower, with the Beaker pots made for burial often surface treated to improve their appearance (Boast 1995). In terms of acquisition of raw materials, the clay to make pottery is readily available compared to other more exotic materials, such as jet or copper that also occur within grave assemblages. The clay fabrics used in Beaker pots exhibit a wide variety of mineral inclusions derived from local lithologies, implying decentralised, locally based production (Hamilton 2002, 48). Therefore, the significance of placing a Beaker pot in a burial is not in its acquisition (of raw resources), which of course may be subscribed with a complex interaction of procurement, but from the obtainment and inclusion of the finished vessel. As Boast asks $(1995,78)$ : 'If the role of the burial goods is to signal the status of the dead in life, why is the most common association in the grave in the Early Bronze Age, for all members of society, a pot that is common in daily use'.

Case (1995a), building on the analysis of Clarke (1970), demonstrates considerable fluidity in the size of Beaker pots placed in a grave and the gender of the deceased, and the number of grave goods. Whilst there are some exceptions (and a less clear chronological sequence of grave assemblages at their time of writing), upper medium size Beakers (1500-200CC) or large size Beakers (2000cc or greater) are often 
associated with multiple grave goods. Likewise, small Beakers (500cc or less) are often but not exclusively associated with children, and are rarely associated with multiple grave goods. There are exceptions, such as Barrow Hills, (Oxfordshire), burial F919, with a small Beaker pot placed in the grave of a child, associated with a high number of grave goods. However, there is a general trend between the size of the Beaker pot and the number of grave goods, and this could indicate a meaning between the size of the Beaker pottery selected for the funerary context and the individual being interred. Likewise, Shepherd (2012) recognises relationships between the gender of the deceased and the shape and decoration of the Beaker pot placed in the grave in burials from northern Britain, again indicating a symbolic linkage between the deceased and the pottery vessel.

A significant aspect of the Beaker pottery placed in inhumations in Britain during the earlier exclusive culture phase, is a clear correlation with Beaker pottery forms found in northwest Europe. The Beaker package has a pan European distribution, although regional variation is evident (Van Linden 2004), and thus arrived in Britain with a preconceived and ascribed belief system, which was adopted in parts of Britain, through what Needham $(2005,178)$ terms the fusion corridor. In this sense the pottery itself can be considered to be part of a belief system that was imported into Britain from Europe, or as Fokkens $(2008,19)$ describes '...decoration of the Beakers involved a cultural process of translating European wide signals into regional contexts'. Therefore, the presence of Beaker pottery can be interpreted as indicating alignment to a wider idea defined to some extent by its material culture, of which Beaker pottery is highly visible. As Jones $(2008,188)$ states, in discussing pottery vessels placed within Beaker period inhumations '..... the presence of the vessel acts a material signifier of identity'.

However, Beaker pots are not included in all graves during the Beaker period in Britain, but the inclusion in some is striking and significant, given the association of the pottery between the realms of the living and the dead, the limited variability in design and decoration over both spatial and chronological dimensions, the local origin of the clays used to make them, and possible associations between Beaker sizes and grave goods, and Beaker shape and decoration and gender of the deceased. Thus from the context of this paper, the inclusion of a Beaker pot within a grave assemblage is interpreted as indicating adoption of a Beaker identity or belief system; a material signifier of identity. If Beaker pottery being included within a grave assemblage does indicate some degree of subscription to a Beaker identity, could the size of the Beaker pot placed into the grave, 
indicate the degree to which an individual has become part of this Beaker world, have access to resources from a wider network; hence the size of Beaker pot in death, represents the degree of Beaker interconnectedness in life? Such an interpretation helps to explain why children generally have smaller Beakers and why larger grave good assemblages are associated with larger Beakers? Such relationships are consistent with the interpretation that a Beaker pot is a cultural identifier in the grave, the size of which indicates the degree of interconnectedness within this Beaker world.

If this stance is accepted, that inclusion of Beaker pottery within the grave is a cultural identifier, conversely when a Beaker pot is omitted from the burial assemblage, is this interpretable as representing a different non-Beaker identity? This idea of multiple identities has been commented on previously. Gibson $(2004 ; 2007)$ applies the term 'a Beaker veneer', highlighting considerable diversity in burial styles during the Beaker period (although some of the dating has subsequently shown the development from the preceding Neolithic traditions to be incorrect). Needham (2016) also describes the spatially exclusive Halberd bearers and Beakers across Britain and Ireland, showing coexistence of two distinct groups between Britain and Ireland during the Beaker period. Likewise, Wilkin (2011) demonstrates different burial traditions in different areas of Scotland, between areas dominated by Beaker style burials and areas with Food Vessel burials and dagger burials, initially with seemingly little overlap between the styles of burial.

The funerary landscape of the Beaker period in southern England is diverse, so instead of providing an approach that is spatially segregated, burials are considered here that exclude a Beaker pot from the grave assemblage, and question whether this represents non-Beaker identities. Whilst, this paper makes no attempt to suggest what the values or beliefs were behind either Beaker or non-Beaker identities, the repeating pattern of Beaker pottery (and more widely Beaker material culture such as archers wrist guards and barb and tanged arrowheads) does suggest some degree of symbolic alignment of world views between people in their treatment of the dead. As Owoc $(2000,2)$ succinctly writes, 'funerary rituals not only function as a means to legitimate and perpetuate the socio-political order, but also reproduce and create, through action, the central values of society. These values are generally represented within and through a set of related symbolic associations which in turn, reference and objectify a cosmological order.' From this perspective, the presence of Beaker pot is considered a symbolic association that 
references a cosmological order, and placed within a grave indicates that an individual was part of a Beaker identity. Shepherd $(2012,277)$ in reference to Beaker burials in northern Britain, writes: 'The universality of the northern British Beaker pattern shows on some level a unity/ideology, whereas the traditions of pot design, went hand in hand with the cultural imperatives underpinning the burial pattern.'

If the Beaker pots within grave assemblages do act as a material signifier of identity and other burials without Beaker pottery are interpreted as non-Beaker identities, this does not equate to a 'reimagined' culture historical perspective. There are not assumptions about the geographic isolation of groups or ethnic or racial coherence of one group as opposed to another; merely, that significant variation exists in the burial record of southern England during the Beaker period that excludes Beaker pottery from grave assemblages, and that this variation can be interpreted as representing differences, rather than homogeneity within society. It is acknowledged that the focus of this interpretation is based around the presence or absence of Beaker pottery within the grave assemblage, but this is the most common artefact to be placed into a Beaker grave, even within the Stonehenge landscape (Peters 2000). As Fitzpatrick (2017, 43) states: 'The key and irreducible component of the Set is seen to be the Bell Beaker whose importance as a vessel used in funerary rites drove its expansion'. The following case studies illustrate this argument of the Beaker period having a number of identities visible in the funerary record in southern England that omit Beaker pottery from the grave assemblage, and are re-evaluations of previously published examples (Figure 1). Whilst the data set considered is small, it highlights some key themes in discussing and interpreting the funerary record of the Beaker period.

\section{The sarsen burial, Durrington Walls, Wiltshire}

The sarsen burial from Durrington Walls was a single inhumation found by a shepherd in 1809 during the pitching of a sheep fold and was visited by Richard Colt Hoare shortly after its discovery (Figure 2). The artefacts from this excavation were rescued by Colt Hoare, with the grave goods included in the publication of Ancient Wiltshire, and are now displayed in Devizes museum (Figure 3). This burial has previously been described as one of several Beaker burials around Durrington Walls (e.g. Thomas, 1999, 181).

Colt Hoare (1812) describes the burial as a flat grave found under a capping stone of sarsen, with the head laid towards the north. The grave goods found with the burial 
were comprised of a sponge finger, a flint dagger, a jet $\mathrm{V}$ button, a Kimmeridge shale pulley ring and two chalk (flint) balls. The burial did not contain a Beaker and the skeleton was left in the grave (Higham and Carey, 2019). Typological analysis of the artefacts, particularly the $\mathrm{V}$ perforated button and sponge finger, (derived from Woodward and Hunter 2015) indicate a date of between 2250-1950BC, although heavy ware is noted on some of the artefacts such as the V perforated button and pulley ring, suggesting some degree of heavy use and/or curation. These artefacts place the burial just after the fission horizon (c. 2250BC) and within the period of diversification of funerary ritual between 2250-1950BC. This date is consistent with the incorporation of flint daggers within funerary assemblages (Friemann 2014).

The materiality of this grave is significant. The body was found under a sarsen stone, a material associated with older stone circles and some long barrows in the region, although there is an association between some Beaker burials and sarsen (see below). The inclusion of grave goods made from raw materials exotic for the region (the $\mathrm{V}$ shaped jet button, Whitby; the Kimmeridge shale pulley ring, Dorset), indicates access to an extended network to obtain materials, although the burial assemblage contained a flint dagger, not a metal one. Can this burial be interpreted as a non-Beaker identity in existence at this time? Were the Beaker pot and metal artefacts deliberately excluded from the funerary representation of this individual, as they referred to a different identity? Healey (2012) makes a similar suggestion for the continued mining of flint, and rejection of metal and Beaker pottery at Grimes Graves, representing the continuation of traditional ways in face of new materials and items during the Beaker period by a native population.

There are parallels with other flint dagger burials in Britain. The date of flint daggers found in Beaker period funerary contexts is grouped to between 2250-2000BC when associated with radiocarbon dates, although Hilted Scandinavian daggers are later from 1950BC (Friemann 2014). These earlier flint daggers are most commonly found in inhumation burials without Beaker pottery in adult male graves (only seventeen of forty three burials listed by Friemann 2014 contained a Beaker pot as well). Although flint daggers are frequently described as part of the Beaker package, they are never found alongside metal objects in funerary contexts and of the seventeen recorded in funerary contexts associated with a Beaker pot, these were all found with Long Necked Beakers (Friemann 2014, 49), a type dated to 2200-2000BC (Needham 2012). 
In the Beaker Instituted phase (2250-1950BC) there is a distinct burial package that includes flint daggers, precludes metals, that sometimes incorporates other artefacts such as pulley rings, cushion stones and sponge fingers, but significantly in the majority of cases does not include a Beaker pot. Does the Durrington Walls sarsen burial define a different identity just after the fission horizon, one that is different to the Beaker identity, although both are defined through their funerary assemblages? The sarsen burial demonstrates that prestige items were not only restricted to Beaker burials; they were obtainable to individuals/groups who practised different burial traditions.

\section{Beaker period burials on the West Kennet Avenue, Avebury}

In 1934-5 and 1939 Alexander Keiller and Stuart Piggott excavated and restored the northern third of the West Kennet Avenue at Avebury (Smith 1965). The avenue consists of pairs of sarsen stones stretching over $2.4 \mathrm{~km}$ from the Avebury Henge, probably through to the Sanctuary at Overton Hill, which also contains a Beaker burial (Cunnington 1931), with construction of the West Kennet Avenue broadly dated to the period c. 25002300 BC (Gillings et al. 2008). Keiller's excavations uncovered four stones with associated inhumations on the West Kennet Avenue, as detailed by Smith (1965) (Table 1; Figure 4). Owing to space constraints only some of these burials will be discussed.

\section{Inhumation by stone hole $18 b$}

Keiller excavated stone hole 18b, knowing that Maud Cunnington (Cunnington 1913) had previously identified a buried sarsen stone at this location. The burial of stone $18 \mathrm{~b}$ had partially destroyed the stone hole and a grave associated with it, but enough survived to clarify the position of the stone hole, its original dimensions and the grave cut. The grave was separated from the stone hole by a wall of chalk $0.12 \mathrm{~m}$ wide, preventing a direct stratigraphic association, with an oval grave cut, $0.9 \mathrm{~m}$ long and $0.6 \mathrm{~m}$ wide (Smith 1965 , 209). The contents of the grave were disturbed by the burying of the sarsen stone, with some of the bones from the burial found in the pit beside the stone. The remains of the burial lacked any grave goods, and no radiocarbon date is available, although the form of the grave and suggested date of construction of the West Kennet Avenue suggests a Beaker period date. Keiller comments on the lack of grave goods: 'A curious feature of 
this burial consisted in the total absence of pottery of any description and it must be concluded in this case that no grave goods were buried with the corpse, unless, of course a vessel was discovered intact a farmer may have taken the "rude urn" as a souvenir of his operation.' (Keiller Archive, Keiller museum).

\section{Inhumation by stone hole $22 b$}

This undisturbed burial was found to the east of stone hole $22 \mathrm{~b}$, although no buried sarsen stone was found. Before the sarsen was removed it had fallen, forcing a large packing stone onto the grave protecting it. The grave was oval, with vertical sides, and a flat base being $1.38 \mathrm{~m}$ by $1.24 \mathrm{~m}$. The body was in a crouched position with its feet to the east and head to the west. The body had been placed on its back, head turned to the right and sloping slightly towards its shoulder, with the legs of the burial bent at the hips and the knees drawn up. Behind the shoulders a carinated bowl had been placed (Figure 5).

The pottery vessel from this grave is unique, having variously been described as 'an unusual carinated bowl' (Pollard and Reynolds, 2010, 129) and 'a decorated bowl of uncertain affinity' (Thomas, 1999 pp 219). The vessel is a flat bottomed bowl with a simple rim, with lower part decorated with incised triangle patterns (Figure 6). The style of the vessel strongly suggests a hybrid bowl fusing elements of Grooved Ware and Beaker pottery styles. The technique and the fabric match those used in Grooved Ware, yet the morphology of the vessel is more similar to Beaker pottery. It is a darker colour more similar to Grooved Ware pots, with circular decoration similar to Beaker styles, and incised triangles. Smith $(1965,229)$ suggests the pot as an 'interaction between RinyoClacton (Grooved Ware) and Beaker traditions'. Cleal and Pollard (2012) describe it as combining motifs from both Grooved Ware and Beaker traditions and was probably dated to the earliest period of Beaker use in the Avebury landscape. Does this hybrid Grooved Ware/Beaker pot represent an early fusion of Beaker and Grooved Ware identities, expressed in the fabric of the monument of the West Kennet Avenue, a symbolic joining of two distinct identities within the Avebury landscape? 


\section{Inhumation by stone hole $25 b$}

The remains of several individuals were found at the base of the stone hole $25 \mathrm{~b}$ and in the filling of the stone burial pit, with much of the burial having been destroyed by the digging of the pit to bury the stone. The remains of the body found in the stone hole were interpreted as being placed in an extension of the stone hole, after the erection of the stone. The grave and stone hole were recorded as being filled with the same packing material, suggesting some degree of contemporaneity. Within the stone burial pit Beaker pottery and more human bone were found, with two adolescents and one adult represented (Smith 1965, 209 -210). Keiller in his notes records 'a remarkable quantity of ox bones' (Keiller Archive, Keiller Museum).

\section{West Kennet burials summary}

These three burials from the West Kennet Avenue demonstrate a range of burial traditions present in the Avebury landscape during the Beaker period. Some are not associated with grave goods, some are associated with Beaker pottery, but interestingly one is associated with pottery that apparently fuses elements of Beaker and Grooved Ware pottery together. In terms of different identities, do these burials along the West Kennet Avenue represent individuals who belonged to different social groups, who co-existed within this monumental landscape? Is the interaction and possible joining of these groups expressed through the half Grooved Ware, half Beaker pot found in a burial on the West Kennet Avenue? Here is a monument, constructed around the time of the insertion of the Beaker set into Britain, which contains inhumations associated with Beaker material culture, inhumations with apparently no material culture and one inhumation containing a pot representing both Beaker and Grooved Ware characteristics. Maybe the West Kennet Avenue, joined to the Avebury Henge, was a physical manifestation of the wider world that these henge users were experiencing and symbolically represents the joining of more than one world view.

\section{Racton Man, Chichester, West Sussex}

This burial is located close to Westbourne in Sussex and was excavated in 1989, after an initial chance find by a metal detectorist. The site was subsequently excavated identifying 
an in-situ crouched inhumation burial of an adult male on his left hand side, orientated NNW-SSE with his head facing east, buried with a bronze dagger, referred to as Racton Man. The body was placed on the old land surface, potentially covered by a small mound of chalk rubble which had since been largely ploughed away. The circumstances of the discovery of the burial and its post excavation analysis are detailed by Needham (2017).

The individual was buried with a bronze dagger, a type considered to be transitional between types 1 and 2, labelled by Needham as type 1c (Needham et al. 2017, 87). A radiocarbon date on bone from the inhumation provided a date of $2455-2145 \mathrm{cal}$ BC (2 sigma, SUERC-55526; Needham et al. 2017, 103), firmly at or just after the fission horizon. There was no Beaker pot placed in the grave assemblage, although the individual clearly had access to elite or rare material objects, in this case a very early bronze dagger.

A number of other dagger burials have been excavated in southern England across the Beaker period. An example is the Milston barrow (Wiltshire) where a dagger was found with a primary crouched inhumation with its head to the northwest, but no Beaker pot was present (Colt Hoare, 1812, 185). Gerloff (1975) describes the Milston example as a flat riveted blade, now recognised as a series 2 dagger, which has been demonstrated to be present from 2100-2000BC, in Needham's (2005) revised chronology. Another example is barrow 3, Barrow Hills (Oxfordshire), which contained an inhumation with a 3 riveted bronze dagger, and again lacks any further grave goods in the burial assemblage. It has a radiocarbon date reported of 2500-1950 cal BC (2 sigma, OxA4355; Barclay and Halpin 1999, 152-153). Racton man is an example of a repeating pattern of burial rite, in the 'Beaker instituted phase', with an early bronze dagger accompanying a single inhumation.

This form of burial is recognised by Wilkin (2011) and also by Needham et al. (2017) who term them dagger burials, and they demonstrate a distinct post-fission burial rite, lacking Beaker pottery. The significance of this repeating pattern of burial can be interpreted as a statement of identity that is distinct to the Beaker identity, due to the exclusion of Beaker pottery (and other Beaker related artefacts) from the grave assemblage. In addition, daggers are not always associated with inhumation, such as the cremation dagger burial at barrow 4, Barrow Hills (Oxfordshire) (Barclay and Halpin 1999, 156). Like the case for the flint daggers, early bronze daggers are not objects exclusive to the Beaker using groups in Britain. Rather, a range of prestige goods are in circulation during this Beaker instituted phase (2250-1950BC). Of these, bronze daggers 
are sometimes included in burials, some of these burials contain individuals interred with Beaker Pots, whilst other burials contain individuals who also have access to prestige goods (bronze), but who are buried without other Beaker material culture in the grave assemblage.

\section{Discussion}

The examples presented here describe different burial traditions that are present during the Beaker period in southern England. However, do these different burial traditions represent different belief systems or identities? This debate hinges on whether the Beaker set, and in particular Beaker pottery, represents an identity and whether the interpretation of Beaker pottery within a grave is a cultural identifier that describes alignment with a wider concept of the Beaker world. If this stance is accepted, then the lack of a Beaker vessel in a burial is significant; it indicates alternative belief systems or identities, separate to, but co-existing with the Beaker identity.

It is also worth emphasising at this point, just what the Beaker set consists of, in terms of interpreting burial patterns as representing different identities. During the Beaker as exclusive culture phase, the artefact assemblage of barbed and tanged arrowheads, Beaker pottery, archers wrist guards and gold hair ties, deposited within grave assemblages, is an imported practice from northern Europe (Needham 2005). However, post the fission horizon at 2250BC, some artefact types are found within both Beaker and non-Beaker graves, such as jet buttons, flint daggers, sponge fingers, pulley rings and bronze daggers. It is then, questionable, whether such artefacts, post the fission horizon, are part of a Beaker set, and would be better described as a range of artefacts in circulation during this time period, available to both Beaker and non-Beaker related burial identities.

However, what these non-Beaker identities represent is a more difficult question to address. Is there a diverse prehistoric landscape in this period that contains different groups of people, some of which are Beaker using and others who are not? Or does the evidence suggest that within a group there was a diversity of social identities, one of which was Beaker associated? Which of course directly questions the archaeological interpretations of what Beaker material culture is? This question has to be at least partly addressed through a chronological perspective, as per Needham's (2005) model. There 
is not a fixed reference of 'Beakerness', with the types and forms of Beaker associated artefacts changing over time. However, recent DNA analysis does suggest that in the Beaker as exclusive culture phase, Beaker burials in Britain are primarily formed from individuals with ancestry from the 'continental Beaker complex', with relatively low numbers of indigenous individuals being represented. This pattern continues throughout the Beaker period and although the indigenous DNA contribution from the British Neolithic population does rise over the Beaker period, it remains a small component overall (with the caveat that only thirty seven British Beaker period individuals were analysed and some of these came from graves not containing a Beaker; Olalde et al. 2018).

In the early Beaker as circumscribed exclusive phase there would have been multiple social identities, as Beaker using individuals must have inserted themselves into a pre-existing social landscape. This pioneering horizon (or circumscribed exclusive phase) must have had at least two distinct identities co-existing to some degree in Britain, the Beaker identity and another, in the example of the West Kennet Avenue a society using Grooved Ware and associated with henges. Is this coexistence of different identities visible and being symbolically expressed through the addition of burials in different styles along the West Kennet Avenue? During this time it is possible to consider, at least initially, a prehistoric social landscape outside of the Beaker identity, as the archaeological record of the 'other' already archaeologically pre-exists, represented by the large monuments in southern England such as henges.

Post the fission horizon, Needham (2005) describes a diversification of burial styles, during the Beaker instituted phase, and Fokkens (2008) more generally discusses regional adaptions to the European wide Beaker phenomena. Multiple burial styles are evident both associated with, and not associated with, Beaker material culture. With Beaker associated burials there are changes in Beaker pottery styles, such as the development of Long Necked Beakers, and also new types of objects being placed in grave assemblages. However, often inhumations are not associated with Beaker pottery. The metal dagger burials are an example of this, and another is presented by the flint dagger burials, exemplified by the sarsen burial at Durrington Walls. Furthermore, Colt Hoare and Cunnington (Colt Hoare 1812) record numerous burials without a Beaker, just primary internments of individual skeletons, sometimes associated with antler (c. 20 primary inhumations associated with antler have been recorded; Carey and Edwards forthcoming). 
The excavations at Barrow Hills, (Oxfordshire), produced a range of burials that date to the period 2500-1750BC (although some of the radiocarbon dates span relatively long time periods) that do not contain Beaker pottery such as barrow 12 with a central inhumation (grave 607) containing a flint flake and a bronze awl dated to 2350-1950 cal BC (2 sigma, BM-2699; Barclay and Halpin 1999, 99); the afore mentioned barrow 3 dagger burial; and possibly graves 4969, barrow 17 pit 1 and barrow 15 pit 1 (Barclay and Halpin 1999). In addition, at Barrow Hills (Oxfordshire), were a range of burials associated with Beaker pottery, some inhumations without grave goods, some inhumations without pottery but containing grave goods, and some inhumations associated with Food Vessels. Needham (2012) sees the use of Food Vessels as being 'a reaction from the rump of society'. However, possibly they are the development of one of a number of different identities being expressed through variation in burial rite during the Beaker period, but different to the Beaker identity. Barclay and Halpin (1999, chapter 9) highlight this variability at Barrow Hills, referring to non-Beaker funerary traditions, in a landscape with Beaker burials.

The often referred to Stonehenge Beaker burial does not have a Beaker pot (Evans 1983), but contains three barbed and tanged arrowheads, an archers brace, three pieces of bluestone and two lumps of grooved chalk; the barbed and tanged arrowheads of the individual appear to have been acquired very late in the life of the individual before they pierced his skin! Field and McOmish $(2016,118)$ refer to the Stonehenge 'Beaker burial' as a possible miscreant. However, the only part of the Beaker culture set associated with this inhumation is a stone wrist guard. Therefore, rather than representing someone who subscribed to a Beaker identity, does this Stonehenge inhumation represent an individual who was not Beaker, but had access to some of the material goods in circulation during this period? The companion burial represents another interesting example, who is related to the Amesbury Archer, is buried close to him, but yet does not have a Beaker in the grave assemblage, which is in conspicuous contrast to the Amesbury Archer (Fitzpatrick 2013).

A further set of examples include the non-Beaker burials at Fordington Farm, Dorset (Bellamy 1991), with the unaccompanied primary inhumations in graves 59 (2347-2039 cal BC 2 sigma; UB-3305) and 70 (2290-190 cal BC 2 sigma; UB-3304). Grave 61 (unphased) contained an inhumation with a barbed and tanged arrowhead in the pelvic region. The deceased had their head on a cattle scapulae and their feet placed on 
the axis vertebrae of the same species; behind the lower legs were two pieces of cattle humerus. Grave 61 is potentially the earliest burial in this group, dated to between 24592201 cal BC (2 sigma; UB-6609). The other inhumation within this group, grave 74, containing an adult male and very small or premature infant, could also date to the period 2250-1950BC, although the stratigraphic relationship was unclear during excavation (Bellamy 1991). However, all the dated examples within this barrow group fall within the Beaker instituted phase, with the possibility of grave 61 pre-dating the fission horizon.

Other more recently excavated examples of unaccompanied inhumations include a burial at Ridgeway Farm, Purton, Wiltshire, with grave 9118 containing the crouched inhumation of a possible male aged 11-13. The body was placed on its right hand side, on a north south axis, with the head to the south, which is opposite to the general body position (although much of the skull was missing through truncation) and was dated to between 2290-2030 cal BC (SUERC-56574; Powell 2017). Grave 4231 outside Little Woodbury Salisbury, contained the redeposited or disturbed remains of at least two individuals, again lacking any form of grave goods. Two groups of bones were separated in the grave, one to the south end of the grave and the other in the centre. Two radiocarbon dates from the two individuals gives date ranges of 2200-1970 cal BC (2 sigma; SUERC47738) and 2130-1900 cal BC (2 sigma; SUERC-41685) (Powell 2015). These examples demonstrate that unaccompanied inhumation, both individually and in multiple occurred during the Beaker as instituted culture phase. Cleal (2005) also lists some non-Beaker associated inhumations in the Avebury landscape, including a possible Beaker period flat grave cemetery at Overton Down, with many inhumations not containing grave goods.

It is necessary to question what Beaker material culture actually is, within the Beaker instituted phase. A range of artefacts are in circulation during the Beaker period from c. 2250BC onwards; however, artefacts such as jet buttons, early bronze daggers and flint daggers are not exclusive to Beaker exchange networks or Beaker burials. Secondly, as the data from West Kennet Avenue and the Durrington Walls sarsen burial show, although funerary practices and construction of identities might have been exclusive, the landscapes these people were buried within were not. These landscapes were accessed by people who subscribed to different burial styles and by extrapolation were constructing different identities. Cleal and Pollard (2012) hint at this association between the interaction of Beaker and non-Beaker societies, indicating that cultural practices did not drastically change in the Wessex ceremonial centres with the appearance 
of Beaker pottery and burials, indicating Beaker material culture was absorbed into regional practices. Healey (2012) suggests that activity at Grimes Graves, which continued throughout the Beaker period, did so by a population who asserted traditional ways and values against innovations (associated with the adoption of Beaker material culture).

So what do these non-Beaker burials actually tell us about the organisation of prehistoric society? Are we discussing groups of peoples (tribes?) or individuals within a Beaker using society? Fowler $(2013,168)$ relates variation in burial styles in northern England between 2200-1700BC to variation in power, identity and social division, although the synthesis of non-Beaker associated burials in southern England is far from complete and this requires redress. However, there is some evidence that can lead us to consider what the Beaker complex was, and how society reacted to it and with it. Some, regions have a much shorted currency of Beaker use, such as southwest Britain (Jones and Quinnell, 2006), whilst other regions have a much longer currency of Beaker use, e.g. Wessex. This indicates different regional or sub-regional responses to the incursion of a new idea or new customs, and a new ways of doing things. In some areas, these new ways seem to have had less appeal and have a short duration of use. In comparison in southern England, especially Wessex, the Beaker burial rite and Beaker pottery use has a much longer currency with a late phase (post 1950BC), possibly referencing an earlier ideal.

The excavation at Over, Cambridgeshire (Garrow et al. 2014) shows that Collared Urn use overlaps with individuals referencing an earlier Beaker burial, before Collared urns and cremations become the dominant burial rite. Is this interpretable as a change in identity (how the dead were treated) and possibly by extension, belief system of the group using this cemetery? As significantly, as well as burial styles changing and different regional reactions to Beakerness, individuals still continue to be buried with Beaker pots during the Beaker as instituted culture phase; the forms of Beaker pottery diversify, but they are still recognisable as Beakers. If the currency of being Beaker had become less during this phase, potentially due to a lower ability to access exchange networks, particularly metals (as argued by Wilkins, 2011), potentially people were demonstrating identity through deliberately non-referencing Beaker material culture. Whether this is represented by individuals within a group or by different groups is unclear, although the regional variation of Beaker burials during this period does indicate this is possibly by 
different groups. Conversely, if it is within group variation that is being expressed through these different burial styles, these identities are being constructed through removing the direct association with Beaker material culture from the grave, such as dagger burials. These burials could be a diversification or elaboration of the Beaker burial tradition (Needham et al. 2018), but if this does represent elaboration of the Beaker burial rite, it has removed a direct reference to a Beaker idea in the grave assemblage.

The more the burial record of the Beaker period is explored, the more evidence comes to light of multiple types of funerary practice that occur in repeating patterns across wider monumental landscapes in southern England, datable to the Beaker Instituted phase; metal dagger burials, flint dagger burials, burials with no grave goods, possibly antler burials and of course Beaker burials. Given the evidence presented, and this is only a small sample of the potential data available from the funerary record for this period, it is suggested that the chronological phases put forward by Needham are amended to include the diversity of non-Beaker related funerary traditions (Table 2). This diversity of funerary traditions in southern England poses some challenging questions. Simply, why is there such diversity of burial practice evident within the Beaker period? What does this diversity of funerary practice represent in terms of construction of identities during the Beaker period? Are the non-Beaker burials in southern England an equivalent of Food Vessel practices in the Beaker instituted phase, more commonly found in northern Britain? Is there a connection between earlier burials not associated with the Beaker set in the Beaker as exclusive culture phase, and later burial styles in the Beaker as instituted culture phase that also omit Beaker material culture from the grave assemblage?

\section{Conclusion}

This paper has presented an initial, and admittedly limited, interpretation of some select evidence of the Beaker period funerary record in southern England, in line with the chronological sequence put forward by Needham (2005). This interpretation is not only consistent with the excavated evidence, but also helps to explain some of the trends visible in the archaeological record of this period. There are numerous inhumations from the British Beaker period that have gone 'under the radar', both in dating programmes and also general discussions of this period, due to a lack of artefacts found during excavation. Likewise, other burials are assigned as Beaker, based on their artefactual 
compositions, although the burials themselves lack Beaker pottery. There is much to be done on this line of enquiry, to accurately date some of these non-Beaker burials and compare them to the new chronology of Beaker use. Such focused research would enable the diversity of Beaker period burial practices in southern England to be recognised, and also compared and contrasted to Beaker period burial styles in northern Britain, where diversity of Beaker burials has received more concentrated research (e.g Fowler 2013; Wilkin 2011). Such synthesis and wider comparison will allow a fuller, more nuanced picture of Beaker period burials across the UK to be developed.

There is great mileage in revisiting older archives to examine the types of what are now recognisable as Beaker period burials. There is a great diversity of form, and a number that do not contain Beaker pottery but contain prestige artefacts. There is a clear need to re-examine the artefactual archive of grave assemblages and to revisit just how often Beaker pottery is associated with such material culture, e.g. jet buttons or sponge fingers? Are certain grave goods only found with Beaker pottery? Is body orientation in graves without grave goods different to the orientation in graves containing Beaker pottery? Do other artefact types only occur outside of burials with Beaker pottery? Do these rules/associations change over time? Does the interpretation of the genetic evidence for Beaker burials change, when individuals are analysed from a multiple identity perspective? Can more DNA evidence from the Beaker period be collected and analysed to specifically include individuals from non-Beaker related burials? These questions require investigation and debate. However, maybe we should question what the Beaker period actually is. We argue for a diverse Chalcolithic/Late Neolithic/Early Bronze Age, where identity and material associations are dynamic, changing and coexisting. The Beaker Package forms a significant part of this society, but it is only one part.

\section{Acknowledgements}

Many people have helped throughout this research. The staff at Devizes Museum have been a huge source of help throughout; thanks especially to David Dawson for his discussions around this subject. The staff at the Keiller museum at Avebury are also thanked for their help, as are the staff at the Ashmoleum Museum and Chichester Museum. Stuart Ladd is acknowledged for information on Beaker burials. Lastly thank you to Charlie Hay for asking obvious and insightful questions, and for discussing the 
project more generally. The SETRiF fund at the University of Brighton generously supported part of this project. The reviewers are also thanked for all their helpful comments and constructive comments that have helped to improve the original manuscript.

\section{Bibliography}

Allen, M. J., Gardiner, J. \& Sheridan, A. (eds) 2012. Is there a British Chalcolithic? People, place and society in the late $3^{\text {rd }}$ millennium. Prehistoric Society Research paper 4. Oxbow: Oxford

Andrews, P. and Thompson, S. 2016. An early Beaker funerary monument at Porton Down, Wiltshire. Wiltshire Archaeological and Natural History Magazine, 109, pp. 38 $-82$.

Barclay, A. and Halpin, C. 1999. Excavations Barrow Hills, Radley, Oxfordshire: Volume I. The Neolithic and Bronze Age complex. Oxford University Committee for Archaeology: Oxford.

Barrowclough, D. 2010. Dating the Early Bronze Age in Northern England: Comparison with Ireland, Scotland and Wales. Red Dagger press: Cambridge. Bellamy, P. S. 1991. The excavation of Fordington Farm round barrow. Proceedings of the Dorset Natural History and Archaeology Society, 113, pp. 107 - 132.

Boast, R. 2002. Chapter 10 Pots as categories: British Beakers, in A Woodward and J D Hill (eds), Prehistoric Britain The Ceramic Basis, pp. 96- 105. Oxbow: Oxford Boast, R. 1995. Fine pots, pure pots, Beaker pots, in I Kinnes and G Varndell, (eds), Unbaked Urns of Rudely Shape. Essays on British and Irish pottery for Ian Longworth, pp. 69-79. Oxbow Books: Oxford.

Brodie, N. 1997. New perspectives on the Bell-Beaker culture. Oxford Journal of Archaeology, 16 (3), pp. 297 - 314.

Brück, J. 2004. Material metaphors. The relational construction of identity in Early Bronze Age burials in Ireland and Britain. Journal of Social Anthropology, 4 (3), pp. $307-333$.

Burgess, C. and Shennan, S. 1976. The Beaker phenomenon: some suggestions, in, C Burgess and R Miket, (eds), Settlement and Economy in the Third and Second Millennia BC. British Archaeological Reports British Series 33, pp. 309-31. BAR: Oxford. 
Case, H. 2004b. Beakers and the beaker culture, in, J Czebreszuk (ed), Similar but different. Bell Beakers in Europe, pp. 11 - 31. Sidestone Press: Leiden.

Case, H. 2004a. Beaker burial in Britain and Ireland. A role for the dead, in, M Besse and J Desideri (eds), Graves and funerary rituals during the late Neolithic and early Bronze Age in Europe (2700 - 2000BC), pp. 195 - 200. BAR: Oxford.

Case, H. 1995a. Chapter 6: Beakers: losing a stereotype, in I Kinnes and G Varndell, (eds), Unbaked Urns of Rudely Shape. Essays on British and Irish pottery for Ian Longworth, pp. 55-65. Oxbow Books: Oxford.

Case, H. 1995b. Some Wiltshire Beakers and their contexts. The Wiltshire Archaeological and Natural History Society Magazine, 88, pp. 1 - 17.

Carey, C. J and Edwards, C. Forthcoming. Antler burials in the Beaker period.

Childe, G. V. 1925. The dawn of European civilisation. Routledge and Keagan Paul ltd: London.

Clarke, D. L. 1970. Beaker Pottery of Great Britain and Ireland. Cambridge University Press: Cambridge.

Cleal, R. and Pollard, J. 2012. The revenge of the native: monuments, material culture, burial and other practices in the third quarter of the $3^{\text {rd }}$ millennium $\mathrm{BC}$ in Wessex, in, $\mathrm{M}$ Allen, J Gardiner and A Sheridan (eds), Is there a British Chalcolithic? People, place and polity in the later $3^{\text {rd }}$ millennium BC, pp. 317 - 332. Oxbow Books: Oxford. Cleal, R. 2005. 'The small compass of the grave': early Bronze Age burial in and around Avebury and the Marlborough Downs, in, G Brown, D Field and D McOrmish (eds), The Avebury landscape. Aspects of the field archaeology of the Marlborough Downs, pp. 115, 132. Oxbow Books: Oxford.

Colt Hoare, R. 1812. Ancient Wiltshire. William Miller: London.

Colt Hoare, R. 1829. Tumuli Wiltunenses; a guide to the barrows on the plains of Stonehenge. J Rutter: Shaftesbury.

Cummings, V. 2017. The Neolithic of Britain and Ireland. Routledge: London. Cunnington, M. 1931. The Sanctuary on Overton Hill, near Avebury. Wiltshire Archaeological And Natural History Society Magazine, 45, pp. 300 - 335.

Cunnington, M. 1913. A buried stone in the Kennet Avenue. The Wiltshire Magazine, 38 , pp. $12-14$

Darvill, T. 2010. Prehistoric Britain. Routledge: Abingdon. 
Evans, J. G. 1983. Stonehenge - the environment in the late Neolithic and Early Bronze Age and a Beaker age burial. Wiltshire Archaeological and Natural History Society Magazine, 78, pp. 7 - 30.

Exon, S., Gaffney, V., Woodward, A. and Yorston, R. 2000. Stonehenge landscapes: journeys through real-and-imagined worlds. Archaeopress: Oxford.

Field, D. and McOrmish, D. 2016. Neolithic horizons. Monuments and changing communities in the Wessex landscape. Fonthill Media: London.

Fitzpatrick, A. P. 2017. The arrival of the Beaker set in Britain and Ireland, in, J T Koch and B Cunliffe, (eds), Celtic from the West 2. Oxbow Books: Oxford. Fitzpatrick, A. 2013. The Amesbury archer and the Boscombe Bowmen. Bell Beaker burials at Boscombe Down, Amesbury, Wiltshire. Wessex Archaeology: Salisbury. Fokkens, H. 2008. Background to Dutch Beakers: A critical review of the Dutch model, in, H Fokkens and F Nicolis (eds), Background to Beakers Inquiries into regional cultural backgrounds of the Bell Beaker complex. Sidestone Press: Leiden. Fowler, C. 2013. The emergent past. A relational realist archaeology of Early Bronze Age mortuary practices. Oxford University press: Oxford. Frieman, C. J. 2014. Double edged blades: re-visiting the British (and Irish) flint daggers. Proceedings of the Prehistoric Society, 80, pp. 33 - 65.

Garrow, D., Meadows, J., Evans, C. and Tabor, J. 2014. Dating the dead: a high resolution radiocarbon chronology of burial within an early Bronze Age barrow cemetery at Over, Cambridgeshire. Proceedings of the Prehistoric Society, 80, pp. 207 $-236$.

Gerloff S. 1975. The Early Bronze Age daggers in Great Britain and a reconsideration of the Wessex culture. Beck: München.

Gibson, A. 2007. A Beaker veneer? Some evidence from the burial record, in, M Larsson and M Parker Pearson (eds), From Stonehenge to the Baltic Living with cultural diversity in the third millennium BC, pp. 47 -64. BAR: Oxford.

Gibson, 2004. Burials and Beakers: seeing beneath the Beaker veneer in Late Neolithic Britain, in, J Czebreszuk (ed), Similar but different. Bell beakers in Europe, pp. 11 31. Sidestone Press: Leiden.

Gibson, A. 2002. Prehistoric pottery. Tempus: Stroud. 
Gillings, M., Pollard, J., Wheatley, D. and Peterson, R. 2008. Landscape of the megaliths: excavation and fieldwork on the Avebury monuments $1997-2003$. Oxbow Books: Oxford.

Greenwell, W. 1877. British Barrows. A record of the examination of sepulchral mounds in various parts of England. Clarendon Press: Oxford.

Guerra-Doce, E. 2006. Exploring the significance of Beaker pottery through residue analysis. Oxford Journal of Archaeology, 25 (3), pp. 247-259.

Hamilton, S. 2002. Between ritual and routine: interpreting British prehistoric pottery production and distribution, in, A Woodward and J D Hill (eds), Prehistoric Britain The Ceramic Basis, pp. 38 - 53. Oxbow: Oxford.

Hawkes, C. and Hawkes, J. 1949. Prehistoric Britain. Penguin Books: London. Healey, F. 2012. Chronology, corpses, ceramics copper and lithics, in, M Allen, J Gardiner and A Sheridan (eds), Is there a British Chalcolithic? People, place and polity in the later $3^{\text {rd }}$ millennium BC, pp. 145 - 163. Oxbow Books: Oxford. Higham, R. and Carey, C. 2019. The sarsen burial at Durrington Walls. Wiltshire Archaeological and Natural History Society Magazine, 112, pp. 74-84 Johnson, M. 2010. Archaeological theory (2 ${ }^{\text {nd }}$ edition). Wiley-Blackwell: Chichester. Jones, A. M., Brunning, R. and McKinley, J. I. 2017. Barrow 4 (G4), Milton Lilbourne, Wiltshire: new analysis and dating of the log coffin burial. Wiltshire Archaeological and Natural History Magazine, 110, pp. 123 - 133.

Jones, A. 2008. How the dead live, in, J Pollard (ed), Prehistoric Britain, pp. 177 201. Blackwell: Oxford.

Jones, A. and Quinnell, H. 2006. Cornish Beakers: new discoveries and perspectives. Cornish Archaeology, 45, pp. 31 - 69.

Needham, S., Kenny, J., Cole, G., Montgomery, J., Jay, M., Davis, M. \& P. Marshall. 2017. Death by combat at the dawn of the Bronze Age? Profiling the daggeraccompanied burial from Racton, West Sussex. The Antiquaries Journal, 97, pp. 65 117.

Needham, S. 2016. The lost cultures of the Halberd bearers: a non-Beaker ideology in later $3^{\text {rd }}$ millennium Atlantic Europe, in, B Cunliffe and T Koch (eds), Celtic from the West 3. Atlantic Europe in the metal ages: questions of shared language. Oxbow Books: Oxford. 
Needham, S. 2012. Case and place for the British Chalcolithic, in, M Allen, J Gardiner and A Sheridan (eds), Is there a British Chalcolithic? People, place and polity in the later $3^{\text {rd }}$ millennium $B C$, pp. 1 - 26. Oxbow Books: Oxford

Needham, S. 2007. Isotopic aliens: Beaker movement and cultural transmissions, in, M Larsson and M Parker Pearson, (eds), From Stonehenge to the Baltic Living with cultural diversity in the third millennium BC, pp. 41 - 46. BAR: Oxford.

Needham, S. 2005. Transforming Beaker culture in North-West Europe; processes of fusion and fission. Proceedings of the Prehistoric Society, 71, pp. $171-217$.

Parker Pearson, M., Chamberlain, A., Jay, M., Richards, M., Sheridan, A., Curtis, N., Evans, J., Gibson, A., Hutchison, M., Mahoney, P., Marshall, P., Montgomery, J., Needham, S., O’Mahoney, S., Pellegrini, M. and Wilkin, N. 2016. Beaker people in Britain: migration, mobility and diet. Antiquity, 90 (351), pp. $620-637$.

Olalde, I., Brace, S., Allentoft, M. E., Armit, I., Kristiansen, K., Booth, T., Rohland, N., Mallick, S., Szécsényi-Nagy, A., Mittnik, A., Altena, E., Lipson, M., Lazaridis, I., Harper, T. K., Patterson, N., Broomandkhoshbacht, N., Diekmann, Y., Faltyskova, Z., Fernandes, D., Ferry, M., Harney, E., de Knijff, P., Michel, M., Oppenheimer, J., Stewardson, K., Barclay, A., Werner Alt, K., Liesau, C., Ríos, P., Blasco, C., Vega Miguel, J., Menduiña García, R., Avilés Fernández, A., Bánffy, E., Bernabò-Brea, M., Billoin, D., Bonsall, C., Bonsall, L., Allen, T., Büster, L., Carver, S., Castells Navarro, L., Craig, O. K., Cook, G. T., Cunliffe, B., Denaire, A., Egging Dinwiddy, K., Dodwell, N., Ernée, M., Evans, C., Kuchař́k, M., Francès Farré, J., Fowler, C., Gazenbeek, M., Garrido Pena, R., Haber-Uriarte, M., Haduch, E., Hey, G., Jowett, N., Knowles, T., Massy, K., Pfrengle, S., Lefranc, P., Lemercier, O., Lefebvre, A., Heras Martínez, C., Galera Olmo, V., Bastida Ramírez, A., Lomba Maurandi, J., Majó, T., McKinley, J. I., McSweeney, K., Gusztáv Mende, B., Modi, A., Kulcsár, G., Kiss, V., Czene, A., Patay, R., Endrődi, A., Köhler, K., Hajdu, T., Szeniczey, T., Dani, J., Bernert, Z., Hoole, M., Cheronet, O., Keating, D., Velemínský, P., Dobeš, M., Candilio, F., Brown, F., Flores Fernández, R., Herrero-Corral, A., Tusa, S., Carnieri, E., Lentini, L., Valenti, A., Zanini, A., Waddington, C., Delibes, G., Guerra-Doce, E., Neil, B., Brittain, M., Luke, M., Mortimer, R., Desideri, J., Besse, M., Brücken, G., Furmanek, M., Hałuszko, A., Mackiewicz, M., Rapiński, A., Leach, S., Soriano, I., Lillios, K. T., Luís Cardoso, J., Parker Pearson, M., Włodarczak, P., Price, T. D., Prieto, P., Rey, P., Risch, R., Rojo Guerra, M. A., Schmitt, A., Serralongue, J., Maria Silva, A., Smrčka, V., Vergnaud, L., 
Zilhão, J., Caramelli, D., Higham, T., Thomas, M. G., Kennett, D. J., Fokkens, H., Heyd, V., Sheridan, A., Sjögren, K., Stockhammer, P. W., Krause, J., Pinhasi, R. Haak, W., Barnes, I., Lalueza-Fox, C. and Reich, D. 2018. The Beaker phenomenon and the genomic transformation of northwest Europe. Nature, 555, pp. 190-196.

Owoc, M. A. 2000. Aspects of ceremonial burial in the Bronze age of south-west Britain. Unpublished $\mathrm{PhD}$ thesis, University of Sheffield.

Parker, Pearson, M., Sheridan, A. and Needham, S. 2013. Bronze Age tree-trunk coffin graves in Britain, in, N D Melton, J Montgomery and C J Knüsel (eds), Gristhorpe Man A life and death in the Bronze Age. Oxbow Books: Oxford.

Parker Pearson, M. 2012. Stonehenge: exploring the greatest stone age mystery. Simon and Schuster: London.

Patten, R. 2012. Trumpington Meadows, Cambridge, an archaeological excavation. Cambridge Archaeological Unit: Cambridge.

Peters, F. 2000. Two traditions of Bronze Age burial in the Stonehenge landscape. Oxford Journal of Archaeology, 19 (4), pp. 343 - 358.

Piggot, S. 1954. Neolithic cultures of the British Isles. Cambridge University Press: Cambridge.

Pollard, J. and Reynolds, A. 2010. Avebury the biography of a landscape. The History Press: Stroud.

Pollard, J. 2002. The nature of archaeological deposits and find assemblages, in A Woodward and J D Hill (eds), Prehistoric Britain The Ceramic Basis, pp. 22 - 33. Oxbow: Oxford.

Powell, A. B., Beach, S. and Leivers, M. 2018. Prehistoric deposition, burial and settlement on Salisbury Plain: archaeological investigations along the new military tracks, 2009-2012. Wiltshire Archaeological and Natural History Magazine, 111, pp. $84-193$.

Powell, A. B. 2017. An early Bronze Age burial, early to middle Iron Age settlement and Romano-British activity at Ridgeway Farm, Purton, Wiltshire. Wiltshire Archaeological and Natural History Magazine, 110, pp. 17 - 55.

Powell, A. B. 2015. Bronze Age and early Iron Age burial grounds and later landscape development outside Little Woodbury, Salisbury, Wiltshire. Wiltshire Archaeological and Natural History Magazine, 108, pp. 44 - 78. 
Rowley-Conwy, P. 2004. The Three Age system in English: new translations of the founding documents. Bulletin of the history of archaeology, 14 (1). pp. 4-15.

Shepherd, A. 2012. Stepping out together: men, women and their Beakers in time and space, in, M Allen, J Gardiner and A Sheridan (eds), Is there a British Chalcolithic? People, place and polity in the later $3^{\text {rd }}$ millennium BC, pp. 257 - 280. Oxbow Books: Oxford

Sherratt, A. 1991. Sacred and profane substances: the ritual use of narcotics in Later Neolithic Europe, in P Garwood, D Jennings, R Skeates and J Toms (eds), Scared and Profane. Proceedings of a conference on archaeology, ritual and religion, Oxford, 1989. Oxford University Committee for Archaeology, Monograph no. 32. Short Run Press: Exeter.

Sheridan, A. 2012. A Rumsfeld reality check: what we know, what we don't know, and what we don't know we don't know about the British Chalcolithic in Britain and Ireland, in, M Allen, J Gardiner and A Sheridan (eds), Is there a British Chalcolithic? People, place and polity in the later $3^{\text {rd }}$ millennium BC, pp. 40 - 55. Oxbow Books: Oxford Smith, I. F. 1965. Windmill Hill and Avebury. Excavations by Alexander Keiller 1925 - 1939. Clarendon Press: Oxford.

Šoberl, L. 2011. Pots for the afterlife: organic residue analysis of British Early Bronze Age pottery from funerary contexts. Unpublished $\mathrm{PhD}$ thesis, University of Bristol.

Thomas, J. 1999. Understanding the Neolithic (second edition). Routledge: London. Thomas, J. 1991. Reading the body: Beaker funerary practice in Britain, in, P Garwood, D Jennings, R Skeates and J Toms (eds), Scared and Profane. Proceedings of a conference on archaeology, ritual and religion, Oxford, 1989. Oxford University Committee for Archaeology, Monograph no. 32. Short Run Press: Exeter.

Van Linden, M. 2004. Polythetic networks, coherent people: A new historical hypothesis for the Bell Beaker Phenomenon, in, J Czebreszuk (ed), Similar but different. Bell beakers in Europe, pp. 35 - 62. Sidestone Press: Leiden

Wilkin, N. C. A. 2013. Food Vessel pottery from early Bronze Age funerary contexts in northern England: a typological contextual study. Unpublished $\mathrm{PhD}$ thesis, University of Birmingham. 
Wilkin, N. C. A. 2011. Grave-goods, contexts and interpretations: towards regional narratives of Early Bronze Age Scotland. Scottish Archaeological Journal, 33, pp. 2137.

Woodward, A. and Hunter, J. 2015. Ritual in Early Bronze Age Grave Goods: An examination of ritual and dress equipment from Chalcolithic and Early Bronze Age graves in England. Oxbow Books: Oxford.

Figure 1: The locations of the case study burials.

Figure 2: The probable location of the sarsen burial from Durrington Walls. The location of the grave was not recorded by Colt Hoare, but its location has been suggested through the presence of sarsen stone, recorded in 1887 (see Higham and Carey 2019).

Figure 3: The grave goods from the sarsen burial, Durrington Walls, showing: left, the original engraving in Ancient Wiltshire (A) and; right, the grave goods of a flint dagger (B), Kimmeridge Shale pulley ring (C) sponge finger (D), a jet V button (E) and two chalk (flint) balls (F). (Images B - F used with permission from Devizes Museum). Figure 4: The location of the burials on the West Kennet Avenue, Avebury, Wiltshire. Figure 5: The excavation of the burial at stone hole 22b, on the West Kennet Avenue, Avebury showing: top, the position of the carinated bowl behind the shoulders in the grave and; bottom, the location of the grave relative to the stone hole. (Scans used with permission from Alexander Keiller Museum, Avebury).

Figure 6: The carinated bowl from the West Kennet Avenue burial, stone hole 22b.

Table 1: Excavated inhumations along the West Kennet Avenue.

Table 2: Revised interpretative sequence, building on Needham's (2005) suggested Beaker period phases.

\begin{tabular}{|l|l|l|l|}
\hline Stone & $\begin{array}{l}\text { Number of } \\
\text { inhumations }\end{array}$ & Grave goods & Other comments \\
\hline Stone $18 \mathrm{~b}$ & 1 & None & Ceramic Bowl \\
\hline Stone $22 \mathrm{~b}$ & 1 & $\begin{array}{l}\text { Ceramic bowl, almost complete. } \\
\text { Possibly early in the Beaker } \\
\text { period, 2450-2250BC }\end{array}$ \\
\hline
\end{tabular}




\begin{tabular}{|l|l|ll|l|}
\hline Stone 25b & 3 & $\begin{array}{l}\text { Beaker, } \\
\text { skeleton }\end{array}$ & $\begin{array}{l}\text { Fragmentary vessel, notched } \\
\text { stamp decoration, burnished } \\
\text { reddish surface. Short necked } \\
\text { Beaker - possibly post 2300BC. } \\
\text { The Keiller archive records the } \\
\text { presence of ox bones in the } \\
\text { burial. }\end{array}$ \\
\hline Stone 29a & 1 & Beaker & $\begin{array}{l}\text { Low carinated Beaker, red } \\
\text { burnished surfaces and cord } \\
\text { impressed beneath the rim. } \\
\text { Likely to date to the early Beaker } \\
\text { as exclusive culture phase 2450 } \\
-2250 \mathrm{BC}\end{array}$ \\
\hline
\end{tabular}

Table 1: Excavated inhumations along the West Kennet Avenue.

\begin{tabular}{|l|l|l|}
\hline Name & Date & Characteristics \\
\hline Chalcolithic: & $2450-$ & Early pioneer groups associated with Beaker material \\
insertion phase & $2250 \mathrm{BC}$ & $\begin{array}{l}\text { culture are present in the UK. Found within wider } \\
\text { native Later Neolithic social landscape. Strict rules } \\
\text { governing identity of the 'Beaker Culture', with a } \\
\text { limited artefact diversity. No 'native' Late Neolithic } \\
\text { burial tradition, thus Beaker inhumations dominate the } \\
\text { archaeological record. Relatively low diversity of } \\
\text { artefact types found within funerary assemblages, } \\
\text { including, Beaker pottery, barbed and tanged }\end{array}$ \\
\hline
\end{tabular}




\begin{tabular}{|l|l|l|}
\hline \multicolumn{2}{|l|}{} & \multicolumn{2}{l|}{$\begin{array}{l}\text { arrowheads, gold hair ties, cushion stones and copper } \\
\text { knives }\end{array}$} \\
\hline FISSION HORIZON & $\begin{array}{l}2250- \\
\text { Identity Phase }- \\
\text { including } \\
\text { Beaker } \\
\text { diversification }\end{array}$ & $\begin{array}{l}\text { Non-Beaker groups with different world views, adopt } \\
\text { inhumation in a range of styles. Beaker inhumations } \\
\text { continue and diversify. An increasingly diverse range } \\
\text { of artefacts types are visible in the archaeological } \\
\text { inhumation record, including antlers, jet buttons, shale } \\
\text { pulley rings, bronze daggers, flint daggers, whetstones } \\
\text { and strike a lights, with these artefact types available } \\
\text { to multiple social groups. Monumental landscapes } \\
\text { were available for inhumation of individuals from } \\
\text { multiple traditions. Development of other pottery } \\
\text { styles alongside Beaker such as Collared Uns and } \\
\text { Food Vessels. }\end{array}$ \\
\hline Early & $\begin{array}{l}\text { Bge } \\
1700 \mathrm{BC}\end{array}$ & $\begin{array}{l}\text { Multiple inhumation burial traditions continue, with } \\
\text { the emergence of Wessex style burials. A range of } \\
\text { pottery styles found in both inhumation and cremation } \\
\text { burials. Some Beaker burials still evident (especially } \\
\text { in Wessex), but the Beaker pottery is often poorly } \\
\text { made, and the Beaker burials are artefact poor, } \\
\text { possibly an archaic form. }\end{array}$ \\
\hline
\end{tabular}

Table 2: Revised interpretative sequence, building on Needham's (2005) suggested Beaker period phases. 


\section{Taylor \& Francis Word Template for journal articles}

\section{Chris Carey ${ }^{a *}$ and Richard Higham ${ }^{\mathrm{a}}$}

${ }^{a}$ School of Environment and Technology, University of Brighton, Brighton, UK

*C.J.Carey@ brighton.ac.uk

Room c636 Cockcroft Building,

School of Environment and Technology,

University of Brighton,

Lewes Road,

Mouslecomb,

Brighton,

East Sussex.

BN2 4GJ.

Provide full correspondence details here including e-mail for the *corresponding author

Dr Chris Carey is a Senior Lecturer in the School of Environment and Technology, specialising in Geoarchaeology and Prehistory.

Richard Higham is a PhD candidate, research archaeological field methods. 


\title{
Multiple identities in the Beaker period: interpreting inhumations out of the Beaker spotlight in southern England
}

\begin{abstract}
The Beaker period in southern England is associated with the appearance of a highly visible set of material culture in the archaeological record, primarily associated with inhumation burials. This Beaker material culture has a long history of archaeological research and has resulted in this period being named after a style of pottery, the Beaker. However, the funerary record for this period is one that exhibits substantial variability. This paper considers how the archaeological narrative of the Beaker period has been constructed and presents a set of examples that exclude Beaker pottery and Beaker artefacts from the grave assemblage, located in southern England. Herein, it is questioned what these burials represent and whether they can be considered Beaker burials or represent other identities co-existing with Beaker using societies. Whilst the Beaker period does not represent an unchanging, fixed set of traditions over time or space, the examples employed demonstrate non-Beaker related burials to have been present from early in the Beaker period. We aim to highlight this important aspect of the archaeological record as requiring more research and synthesis, and promote discussion of non-Beaker identities during this dynamic period of prehistory.
\end{abstract}

Keywords: Beaker period, identity, inhumation, Beaker pottery

\section{Introduction}

Since Thomsen developed a three age system of stone, bronze and iron (RowleyConwy, 2004), archaeological investigation has utilised chronological ages to denote periods of archaeological continuity and change. The utilisation of chronological ages reached a zenith when they were bound up with the notion of archaeological cultures, across both time and also space (Childe 1925). The processual revolution of the 1960s criticised culture history as an inadequate framework for interpreting the past (Johnson 2010), and although the notion of distinct and unified archaeological cultures fell out of use, the application of conventional time periods remain within the archaeological 
literature. Whilst many archaeologists have argued against the sensibility of using reference to the Neolithic), owing to the underlying implication of social, technological and cultural/ideological homogeneity, the use of these terms has persisted; this is significant as the use of such chronological separators implies a sequence of monoideological views of the past, especially in relation to prehistory.

The arrival of the Beaker complex in southern England is an example where a time period is bound up with the notion of an archaeological culture; the Beaker period. However, this period also presents an opportunity to investigate the notion of ideological variation in the past and to question the funerary record of this time period, as one that could contain multiple identities. The date of the Beaker using phase in Britain is from 2450BC through to a very late phase up to $c$. 1650BC (Needham 2005), although significant regional variation exists in adoption and longevity of Beaker style burials (for example see Jones and Quinnell 2006).

Within southern England, Beaker burials have been the subject of sustained research, particularly in Wessex, starting with the work of early Antiquaries e.g. Colt Hoare (1812), through to more recent discoveries such as the Amesbury Archer (Fitzpatrick 2013). There have been multiple typological schemes applied to Beaker pots in Wiltshire (e.g. Case 1995b) as well as more broadly (e.g. Clarke 1970; Needham 2005), focusing on various decorative and shape categorisations. As a consequence of this long history of research the period is named after the type of pottery associated with it, the Beaker (e.g. Boast 1995, 69), and although variation in the archaeological record not associated with Beaker pottery is noted during this time period, Beaker burials still dominate the archaeological narrative (e.g. Cummings 2017, chapter 9). Is it questionable that this 'Beaker period' has been over-stated within the archaeological literature and is it possible that the arrival, adoption and use of the Beaker package in southern England is one of multiple identities in existence during this time period?

This theme, whilst not yet explored in detail in southern England, has been investigated in northern Britain and Scotland, where burials associated with Food Vessels and Beaker pots chronologically overlap and initially occupy separate areas (Wilkin 2011; Shepard 2012). However, the Food Vessel funerary record of southern England is less numerous and is not spatially distinct, with Beaker burials seemingly dominating the funerary record of this time (e.g. Field and Mcormish 2017; Bowden et al. 2017). 
Unquestionably, the arrival and adoption of the Beaker set in southern England is a highly

\section{Defining the Beaker period}

The British Chalcolithic has recently been the subject of debate (see Allen, et al. (eds) 2005), with discussion of including the term Chalcolithic within the archaeological narrative for the British Isles, to define a distinct copper using phase, 2450-2250BC, which is synchronous with the adoption of Beaker material culture. Needham (2005) provides a clear chronological framework for the adoption and use of Beaker material culture within the UK, and this framework is adopted in this contribution. Within this model there is an initial circumscribed exclusive Beaker culture between 2450-2250BC. This early phase utilises a rather limited number of artefact associations in funerary deposits and coexists alongside native Later Neolithic tradition/s. This is followed by a fission horizon, at c. 2250BC. After this fission horizon the Beaker culture in Britain is an instituted culture (2250-1950BC), witnessing a diversification of Beaker pottery types and artefact associations. In the instituted culture phase, Beaker culture is no longer a select identity, but becomes mainstream, and as a consequence of this the need to maintain an identity in relation to the 'other' has seemingly reduced, allowing diversification of Beaker cultural traditions. The meanings of Beaker culture change and evolve, and new styles of pottery start to be used (e.g. Food Vessels and Collared Urns), and in some cases Beaker pottery starts to be excluded from grave assemblages. Finally, there is a Beaker as past reference phase (1950-1650BC) that typically produces poorly furnished graves, possibly of a minority of society who seemingly associate themselves with a Beaker ancestry, with a variety of other burial practices evident at this time (see below). 
This is a useful way of framing the ingression and subsequent adoption of the highly visible Beaker material culture into the British prehistoric social landscape. Recent research has identified several early Beaker burials as isotopic aliens, pioneers that transported with them the early Beaker package into the UK (Needham 2007; Sheridan 2012). The Beaker People Project has shown that whilst there is some mobility in the Beaker period, a relatively low number of early pioneers (isotopic aliens) arrived into the UK from the continent (Parker Pearson et al. 2016). Whilst it is clear that the Beaker 'idea' was adopted and then later diversified within Britain, there has been relatively little consideration of the social landscape outside of the Beaker culture during this period within southern England.

\section{Approaches to analysing Beaker period funerary practices}

The archaeological narrative of the Beaker period in southern England has been primarily constructed from the excavation and interpretation of inhumation burials. This analysis and interpretation of the Beaker funerary record has been influenced by changes in archaeological theory. As a crude dissection, there are three key stances of archaeological thought that have strongly influenced the narrative of this period (Wilkin 2011). These can be summarised as culture history from $c .1910-1965$, processual systems theory from $c .1965-1985$ and then post processual frameworks from $c .1985$ onwards (dates from Darvill 2010, 13).

Each of these interpretative stances brought a different perspective and process to analysing and interpreting the funerary record of the Beaker period. Culture history related assemblages of material culture to groups of people, often defined by ethnicity or race (Johnson 2010). The use of culture historical models was inherently bound up with ideas of invasion causing the spread of material culture typified by the often quoted (Hawkes and Hawkes, 1949) invasion of Britain by the Beaker folk. Whilst various versions of the culture history model of the Beaker infiltration into Britain were proposed, the inference was that the Beaker people came to Britain and attained some form of ascendancy over native populations.

The processual revolution of the mid to late 1960s in some ways had a dramatic impact on the interpretation of the Beaker period, primarily through the work of Clarke (1970) who applied statistical modelling (matrix analysis) of measurements of Beaker 
pots, to create a new typo-chronological scheme for the uptake and use of Beaker pottery Beaker pottery, with the new typo-chronological sequence used to explain in more detail the sequence of the spread of Beaker people across Britain and regional variation in Beaker pottery styles.

Towards the end of the processual period and at the start of the post processual movement, the interpretation of Beaker burials focused on the rise of the individual, indicating a shift from a group centred to ego centred society, with certain individuals having access to prestige goods and resources (Thomas 1991, 34). Post processual approaches diversified and developed a range of interpretations of Beaker funerary traditions, utilising explanations such as creation of memory and myth, and the construction of identity through relational aspects of people and objects (e.g. Brück 2004), which in some studies has been applied to burial styles over a regional scale (e.g. Fowler 2013). Within post processual interpretations, the standard models of acquired status through prestige goods were replaced with relational consideration of material assemblages, and how grave assemblages reflect the social identity, connections and relationships of the deceased. Some recent work on interpreting Beaker period funerary assemblages has adopted a more contextual approach (Wilkin 2011; 2013), creating a balanced and closer relationship between interpretation and data collection, using a regional perspective.

Each approach has provided new insights into the reasons for the diversity and differences within the funerary record of the Beaker record. Using the adoption of these different interpretative lenses significant questions are contested. Why was there such diversity of funerary practice at this time? Why do the grave assemblages contain pottery styles that are current over wide geographic spreads? Does the presence of Beaker material culture in the archaeological record represent a distinct social identity or belief system? What was the reaction of the indigenous population to the arrival of these new symbols and items? And, can we equate Beaker pottery and material with specific groups of people? To question the perspective of non-Beaker identities during this period, it is now necessary to consider the funerary landscape of the period in southern England. 


\section{Funerary context and the Beaker package}

The funerary record from the Beaker period contains significant variation, with inhumations occurring in flat graves, and under and within barrows. There is a spectrum of inhumation practices, with some well-furnished graves such as the Amesbury Archer (Fitzpatrick 2013) through to single inhumations with only a Beaker pot, e.g. the Sanctuary burial, Avebury, (Cunnington 1931). Using the chronological framework described above, the initial exclusive phase witnessed a low number of burials associated with a limited artefact range. Although some of these early burials displayed large numbers of artefacts, the variety of artefacts is still limited (Needham 2005; Sheridan 2012), with early copper knives, Beaker pots, barbed and tanged arrowheads, stone wrist guards and occasional gold hair ties (ear rings) present. Healey (2012) highlights the paucity of evidence for a tradition of inhumation in the British Isles, prior to the adoption of this Beaker burial style, strongly indicating that Beaker inhumations were an intrusive element, rather than an adaption of a pre-existing burial custom. Following the fission horizon there is a diversification of Beaker pottery types in the instituted phase (22501950BC), with an increasing array of funerary grave goods, including jet buttons, pulley rings, boars tusks, battle axes, whet stones, bronze knives/daggers, barbed and tanged arrowheads and flint daggers, as some of the more common types (Case 2004a).

However, these grave goods occur in varying proportions in different inhumations and are often not present. It is unclear what social rules governed the inclusion of these different grave goods within burials, although commonly argued stances are social status (e.g. Case 1995a; Brodie 1997), and relational aspects between the deceased and the societies and the landscapes that they lived within (Brück 2004; Fowler 2013). Grave goods are often exotic items, utilising raw materials that were sourced many miles away from the location of the burial. This has been interpreted to indicate extensive exchange routes as a feature of the Beaker culture across Europe, and part of the identity of being Beaker (Needham 2007). In contrast, the Beaker pot is normally made from local clays (Gibson 2002; Hamilton 2002, 48) and consequently, Beaker graves can contain a collection of materials, which have been acquired from a range of resources, from local to sometimes international scales. Finally, in the Beaker as past reference phase (1950$1650 \mathrm{BC}$ ) there are poorly furnished graves of a minority in society associating themselves with a Beaker ancestry, often buried with poorly made Beaker pots. 
Beaker burials are not only restricted to single inhumation burials and variability 2017). The Boscombe Bowmen are an example of a multiple burial of at least 5 adult males, a teenager, and one, possibly two children, and seven Beaker pots (Fitzpatrick 2013). Other examples of multiple burial are Trumpington Meadow, Cambridge, with two individuals buried toe to toe, with a Beaker pot placed close to each head (Patten 2012), and stone hole 25b on the West Kennet Avenue with 3 individuals represented (Smith 1965).

Fitzpatrick (2013, chapter 9) highlights the presence of timber chambers within some early Beaker graves providing access to the contents of the grave, potentially allowing the removal/addition of grave goods and bones, such as the disarticulated and partial skeleton of a female in grave 5225 on Porton Down, (Andrews and Thompson 2016). The revisiting and rearranging of body parts and grave goods is likely to have been a significant component of at least some Beaker burials. Other factors important in the symbology of Beaker burial are body orientation, position of artefacts relative to the body, and the size of the grave cut. Bodies within Beaker graves in southern England are interred on a general north-south axes, indicating some wider aspect of belief or meaning behind orientation of the body in the grave (Shepherd, 2012 274). Thomas (1991) demonstrates a relationship between increasing grave size and the increasing number of artefacts placed in the grave, including more than one Beaker pot, possibly indicating larger graves had more grave furniture included in them. Likewise, the position of artefacts within Beaker graves is important, with common areas for the positioning of items being close to the head, in front of the chest, behind the back and at the feet (Brück 2004). Shepherd (2012) recognises gender preferences for orientation in Beaker burials from East Yorkshire and northeast Scotland. A prevalent east/west axis of body alignment exists in the northern British burials (although variation does exist), which is different to the general north-south axis in southern England, suggesting regional adaptions to the Beaker phenomena.

During this period there was also adoption of different funerary traditions, alongside the Beaker inhumation style. Post the fission horizon and alongside the diversification of grave goods found within Beaker graves, there is adoption of Food Vessel burials initially associated with inhumations, but also subsequently cremations. Food Vessels are more commonly found within Northern Britain, although examples of 
Food Vessel burials do occur in southern England, they are relatively low in number; for associated with barrows. The date range for Food Vessel use in Scotland is suggested as between 2140-1980 cal BC and 2020-1865 cal BC (Wilkin 2011), with relatively few dates for Food Vessel burials within southern England, the majority of these burials having been excavated by early Antiquarians. At Bulford, Wiltshire, a cremation burial associated with a miniature Food Vessel is suggested to date between 1900-1750BC by Parker Pearson $(2012,153)$ and another recently excavated example at Porton Down Wiltshire, of an infant with a miniature Food Vessel did not have enough bone material for dating (grave 5116; Anderson and Thompson 2016). In barrow 12 grave 605 at Barrow Hills (Oxfordshire), a Food Vessel accompanied the inhumation of a child dating to 2350-1750 cal BC (2 sigma, OxA-1884) placed above an earlier cremation (Barclay and Halpin 1999, 101).

There was also widespread use of Collared Urns primarily associated with cremation burials in the later phases of the Beaker period across southern England. Wilkin $(2013,52-53)$ from a synthesis of burials in northern Britain provides a start date for the use of Collared Urns in funerary rites, which does do not begin until the end of the 21 st or the start of the 20th century BC. Importantly, there is overlap with the end of the Beaker instituted phase and the Beaker as past reference phase. Grave 9647 from Area 7 of the defence training estate on Salisbury plain contained an inverted Collared Urn over the burial of an infant and provided a date from cremated bone of 2030-1880 cal BC (SUERC - 50593; Powell et al. 2018). Likewise, Garrow et al. (2014) from excavations at Over Cambridgeshire, interpret an overlap between the earliest deposition of Collared Urn cremations and Beaker related inhumations within the Low Grounds cemetery; the earliest burials associated with Collared Urns within barrow 12 were modelled to be c.1900BC, overlapping or pre-dating the last unaccompanied infant inhumations referencing a 'rich' Beaker flat grave. A less common form of pottery also found in funerary contexts in southern England are Accessory Vessels, and although relatively low in number, some have been found with well-furnished burials, such as Preshute G1a (Woodward and Hunter 2015, 448) and the log coffin burial at barrow 4, (G4a) Milton Lilbourne. The associated radiocarbon dates with (G4a) Milton Lilbourne barrow suggest a date for Accessory Vessel use in Wessex post 2000BC (Jones et al. 2017) and this is 
consistent with the set of four dated examples from northern Britain reported by Barrowclough (2010).

Tree-trunk burial is also visible as a distinct burial style during the Beaker instituted phase and Beaker as past reference phase, with a probable start date in the $22^{\text {nd }}$ century BC. In four cases (from sixty five listed), Beaker pottery has been found within tree-trunk burials and nine times tree-trunk burials have been associated with Food Vessels (Parker Pearson et al. 2013). The style of burial occurs across the UK, although there are regional concentrations. One concentration is focused in the Wessex region, with the Wessex examples appearing to have a start date after 2000BC, which is later than in northern Britain (Parker Pearson et al. 2013; Jones et al. 2017). However, Barrow Hills (Oxfordshire) flat grave 950 produced a radiocarbon date of 2290-1960 cal BC (2 sigma; BM2703) and is one of the four examples associated with a Beaker pot, suggesting that some tree-trunk burials could date to the Beaker instituted phase within southern England (2250-1950BC). This style of burial is generally associated with inhumation burial, although cremation is recorded in thirteen cases, with provision of grave goods varying, although some tree-trunk burials contain rare types of grave goods, such as metal daggers (Parker Pearson et al. 2013).

However, within southern England, seemingly the most common form of burial for the Beaker period is a single inhumation accompanied by a Beaker pot, and sometimes other grave goods. Critically, the inclusion of one or more Beaker pots within a grave would not represent an interpretative archaeological problem, if all inhumations from this period did indeed include Beaker pottery. Contrary to Thomas (1991, 34): 'Almost all British Beaker graves contain a Beaker vessel, with the exception of a few late examples', there are burials that do not contain Beaker pottery, pre Needham's (2005) Beakers as past reference phase. In Ancient Wiltshire Colt Hoare (1812) describes many primary inhumations uncovered during the digging of barrows that did not include either grave goods or pottery.

Consequently, such burials do not feature prominently in the descriptions of Ancient Wiltshire, or in later research that utilised this significant archive of excavated material. For example, barrow 51 'two skeletons were found with their heads laid towards the north, one an adult, the other a young person' (Colt Hoare 1829, 26) or barrow 22 'a skeleton' (IBID, 16). It is clear that Colt Hoare and Cunnington (the lead 'excavator') understood the difference between primary and secondary inhumations within barrows: 

- but it was reserved for Mr. Cunnington of Heytesbury, to investigate them in a much more perfect manner, and to ascertain, that although sepulchral deposits had been found in the upper part of the tumulus, yet that the primary internment was always placed on the floor of the barrow, and generally within a cist cut into the chalk" (Colt Hoare 1829, B). It is therefore highly likely that some of these primary inhumations recorded by Colt Hoare (1812) that are not associated with grave goods date from the Beaker period.

Needham (2005), using the associations of Beaker grave assemblages, separates Beaker burials into three phases (described above). The junction of the exclusive and instituted (emergent) packages is focused on three significant and unusual funerary groups: Irthlingborough 1, Gravelly Guy and Rudstone 68, although the Rudstone 68 funerary assemblage does not contain a Beaker pot (Greenwell 1887, 262-269). Case (2004a) also recognises distinct variation in Beaker funerary practice and lists five types of 'Beaker' burials; his group 5 are burials including men, women and children forming part of the Beaker set of burials without Beaker pottery.

So whilst a Beaker burial styles has often been discussed, it is clear that examples of inhumations exist from this time period that do not contain Beaker pottery. It is highly likely that many inhumations from the Beaker period have been more recently excavated without any form of grave goods, but given their lack of grave good assemblages have not been radiocarbon dated or further investigated (Gibson 2004; 2007) and as such are under-represented in the archaeological literature. It is also apparent that as well as inhumations without grave goods, some people were interred with extensive numbers of grave goods or highly valued grave goods, but without a Beaker pottery vessel.

It is these inhumations that do not contain a Beaker pot in the grave assemblage that are discussed in this paper. The question, therefore, of what a Beaker pot in a grave assemblage represents, becomes critical. Can an individual who is buried without a Beaker pot, still be considered an individual who was referencing a Beaker identity? This might be considered a circular argument, i.e. a grave without a Beaker pot is not a Beaker grave, but can it be interpreted that this non-inclusion of a Beaker pot was in fact very significant? As Pollard $(2002,28)$ notes: 'The fact that pottery occurs in Earlier Bronze Age burials with such frequency is so readily accepted that we rarely ask why this should be so.' 


\section{Beaker Pots: Purpose and identity}

Needham's $(2005,210)$ chronology for the Beaker period describes: '... at least three definable phases of quite different character and, moreover, with different relationships to the contemporary 'non-Beaker' culture'. It is this non-Beaker culture that forms the focus of the examples below, but what is meant by non-Beaker culture? Or as importantly, what is meant by Beaker culture? Fitzpatrick $(2013$, 193) provides a summary of the reasons previously sought to explain the Bell Beaker package and describes three models of (i) ethnicity and immigration; (ii) status and ranked societies, and (iii) belief systems. He acknowledges that these three categories are not mutually exclusive, but concludes that none of these ideas are convincing enough to explain a panEuropean distribution. However, the fact that the Bell Beaker set does have a pan European distribution, indicates that the Beaker pot did have a symbolic significance, even if the exact meanings/symbolism changed over time and space.

The argument for Beaker pots representing drinking vessels (e.g. Burgess and Shennan 1976, 310-311; Sherratt 1991) is questioned by Case (1995a). More recent analyses have shown some Beakers from funerary assemblages to have been used in cooking, primarily associated with animal fats (Šoberl 2011), although Guerra-Doce (2006) infers a variety of uses for Beakers including drinking, as cremation receptacles and also copper smelting, with all of these activities associated with the process of transformation. Case (2004b) interprets the Beaker pot, and the associated grave goods (stone wrist guards, barbed and tanged arrowheads, and copper alloy knives) as symbolic hunting equipment. The problem with such an interpretation is that it does not explain why such symbolic hunting equipment became so popular over so much of Europe, or why many inhumations contain only Beaker pots with no other grave goods.

Thomas (1991) recognises the grave assemblage as referring to activities which are structuring agencies in society, with the Beaker pot specifically referencing the preparation and consumption of food and drink. Brodie (1997), whilst acknowledging that Beaker pottery in graves cuts across all dimensions of social stratification, interprets the Beaker pots as produced by, and representing, the female (domestic sphere) in burial ritual within a male dominated society. Needham (2007, 44), interprets the Beaker package as: 'The burials featuring this package, or at least part of it, represent individuals entitled to exceptional burials, due to their role as exceptional communicators with the otherworld'. In this case the otherworld refers to non-Beaker areas, and hence such an 
interpretation is understandable in the pioneering phases of Beaker movement into new pottery style, unless other identities are visible. Fokkens (2008) interprets the selection of Beaker artefacts in burials to represent the consciously constructed identities of exemplary ancestors, with men represented as archers and warriors, in some ways referencing an ideal or image of the Beaker identity.

Needham $(2005,209)$ describes the Beaker culture as one of an initial circumscribed exclusive culture, before becoming an instituted culture post 2250BC, explicitly defining the Beaker package as representing a cultural identity. Resulting from an analysis of Beaker pot size and grave good assemblages, Case (1995a, 63) suggests in reference to the Beaker pot: 'These plainly had symbolic significance, perhaps simply to assert identity in another world'. Both these interpretations for the incorporation of Beaker pottery in the grave move toward an association with cultural identity. Boast (2002) notes regional variations in Beaker style and decoration in the UK, but argues against using variation for the identification of regional (cultural) groupings.

The forms of the Beaker pots selected for grave assemblages reflected those used in life, although the quality of the fabric is often lower, with the Beaker pots made for burial often surface treated to improve their appearance (Boast 1995). In terms of acquisition of raw materials, the clay to make pottery is readily available compared to other more exotic materials, such as jet or copper that also occur within grave assemblages. The clay fabrics used in Beaker pots exhibit a wide variety of mineral inclusions derived from local lithologies, implying decentralised, locally based production (Hamilton 2002, 48). Therefore, the significance of placing a Beaker pot in a burial is not in its acquisition (of raw resources), which of course may be subscribed with a complex interaction of procurement, but from the obtainment and inclusion of the finished vessel. As Boast asks $(1995,78)$ : 'If the role of the burial goods is to signal the status of the dead in life, why is the most common association in the grave in the Early Bronze Age, for all members of society, a pot that is common in daily use'.

Case (1995a), building on the analysis of Clarke (1970), demonstrates considerable fluidity in the size of Beaker pots placed in a grave and the gender of the deceased, and the number of grave goods. Whilst there are some exceptions (and a less clear chronological sequence of grave assemblages at their time of writing), upper medium size Beakers (1500-200CC) or large size Beakers (2000cc or greater) are often 
associated with multiple grave goods. Likewise, small Beakers (500cc or less) are often goods. There are exceptions, such as Barrow Hills, (Oxfordshire), burial F919, with a small Beaker pot placed in the grave of a child, associated with a high number of grave goods. However, there is a general trend between the size of the Beaker pot and the number of grave goods, and this could indicate a meaning between the size of the Beaker pottery selected for the funerary context and the individual being interred. Likewise, Shepherd (2012) recognises relationships between the gender of the deceased and the shape and decoration of the Beaker pot placed in the grave in burials from northern Britain, again indicating a symbolic linkage between the deceased and the pottery vessel.

A significant aspect of the Beaker pottery placed in inhumations in Britain during the earlier exclusive culture phase, is a clear correlation with Beaker pottery forms found in northwest Europe. The Beaker package has a pan European distribution, although regional variation is evident (Van Linden 2004), and thus arrived in Britain with a preconceived and ascribed belief system, which was adopted in parts of Britain, through what Needham $(2005,178)$ terms the fusion corridor. In this sense the pottery itself can be considered to be part of a belief system that was imported into Britain from Europe, or as Fokkens $(2008,19)$ describes '...decoration of the Beakers involved a cultural process of translating European wide signals into regional contexts'. Therefore, the presence of Beaker pottery can be interpreted as indicating alignment to a wider idea defined to some extent by its material culture, of which Beaker pottery is highly visible. As Jones $(2008,188)$ states, in discussing pottery vessels placed within Beaker period inhumations '..... the presence of the vessel acts a material signifier of identity'.

However, Beaker pots are not included in all graves during the Beaker period in Britain, but the inclusion in some is striking and significant, given the association of the pottery between the realms of the living and the dead, the limited variability in design and decoration over both spatial and chronological dimensions, the local origin of the clays used to make them, and possible associations between Beaker sizes and grave goods, and Beaker shape and decoration and gender of the deceased. Thus from the context of this paper, the inclusion of a Beaker pot within a grave assemblage is interpreted as indicating adoption of a Beaker identity or belief system; a material signifier of identity. If Beaker pottery being included within a grave assemblage does indicate some degree of subscription to a Beaker identity, could the size of the Beaker pot placed into the grave, 
indicate the degree to which an individual has become part of this Beaker world, have represents the degree of Beaker interconnectedness in life? Such an interpretation helps to explain why children generally have smaller Beakers and why larger grave good assemblages are associated with larger Beakers? Such relationships are consistent with the interpretation that a Beaker pot is a cultural identifier in the grave, the size of which indicates the degree of interconnectedness within this Beaker world.

If this stance is accepted, that inclusion of Beaker pottery within the grave is a cultural identifier, conversely when a Beaker pot is omitted from the burial assemblage, is this interpretable as representing a different non-Beaker identity? This idea of multiple identities has been commented on previously. Gibson $(2004 ; 2007)$ applies the term 'a Beaker veneer', highlighting considerable diversity in burial styles during the Beaker period (although some of the dating has subsequently shown the development from the preceding Neolithic traditions to be incorrect). Needham (2016) also describes the spatially exclusive Halberd bearers and Beakers across Britain and Ireland, showing coexistence of two distinct groups between Britain and Ireland during the Beaker period. Likewise, Wilkin (2011) demonstrates different burial traditions in different areas of Scotland, between areas dominated by Beaker style burials and areas with Food Vessel burials and dagger burials, initially with seemingly little overlap between the styles of burial.

The funerary landscape of the Beaker period in southern England is diverse, so instead of providing an approach that is spatially segregated, burials are considered here that exclude a Beaker pot from the grave assemblage, and question whether this represents non-Beaker identities. Whilst, this paper makes no attempt to suggest what the values or beliefs were behind either Beaker or non-Beaker identities, the repeating pattern of Beaker pottery (and more widely Beaker material culture such as archers wrist guards and barb and tanged arrowheads) does suggest some degree of symbolic alignment of world views between people in their treatment of the dead. As Owoc $(2000,2)$ succinctly writes, 'funerary rituals not only function as a means to legitimate and perpetuate the socio-political order, but also reproduce and create, through action, the central values of society. These values are generally represented within and through a set of related symbolic associations which in turn, reference and objectify a cosmological order.' From this perspective, the presence of Beaker pot is considered a symbolic association that 
references a cosmological order, and placed within a grave indicates that an individual was part of a Beaker identity. Shepherd $(2012,277)$ in reference to Beaker burials in northern Britain, writes: 'The universality of the northern British Beaker pattern shows on some level a unity/ideology, whereas the traditions of pot design, went hand in hand with the cultural imperatives underpinning the burial pattern.'

If the Beaker pots within grave assemblages do act as a material signifier of identity and other burials without Beaker pottery are interpreted as non-Beaker identities, this does not equate to a 'reimagined' culture historical perspective. There are not assumptions about the geographic isolation of groups or ethnic or racial coherence of one group as opposed to another; merely, that significant variation exists in the burial record of southern England during the Beaker period that excludes Beaker pottery from grave assemblages, and that this variation can be interpreted as representing differences, rather than homogeneity within society. It is acknowledged that the focus of this interpretation is based around the presence or absence of Beaker pottery within the grave assemblage, but this is the most common artefact to be placed into a Beaker grave, even within the Stonehenge landscape (Peters 2000). As Fitzpatrick (2017, 43) states: 'The key and irreducible component of the Set is seen to be the Bell Beaker whose importance as a vessel used in funerary rites drove its expansion'. The following case studies illustrate this argument of the Beaker period having a number of identities visible in the funerary record in southern England that omit Beaker pottery from the grave assemblage, and are re-evaluations of previously published examples (Figure 1). Whilst the data set considered is small, it highlights some key themes in discussing and interpreting the funerary record of the Beaker period.

\section{The sarsen burial, Durrington Walls, Wiltshire}

The sarsen burial from Durrington Walls was a single inhumation found by a shepherd in 1809 during the pitching of a sheep fold and was visited by Richard Colt Hoare shortly after its discovery (Figure 2). The artefacts from this excavation were rescued by Colt Hoare, with the grave goods included in the publication of Ancient Wiltshire, and are now displayed in Devizes museum (Figure 3). This burial has previously been described as one of several Beaker burials around Durrington Walls (e.g. Thomas, 1999, 181).

Colt Hoare (1812) describes the burial as a flat grave found under a capping stone of sarsen, with the head laid towards the north. The grave goods found with the burial 
were comprised of a sponge finger, a flint dagger, a jet $\mathrm{V}$ button, a Kimmeridge shale skeleton was left in the grave (Higham and Carey, 2019). Typological analysis of the artefacts, particularly the $\mathrm{V}$ perforated button and sponge finger, (derived from Woodward and Hunter 2015) indicate a date of between 2250-1950BC, although heavy ware is noted on some of the artefacts such as the $\mathrm{V}$ perforated button and pulley ring, suggesting some degree of heavy use and/or curation. These artefacts place the burial just after the fission horizon (c. 2250BC) and within the period of diversification of funerary ritual between 2250-1950BC. This date is consistent with the incorporation of flint daggers within funerary assemblages (Friemann 2014).

The materiality of this grave is significant. The body was found under a sarsen stone, a material associated with older stone circles and some long barrows in the region, although there is an association between some Beaker burials and sarsen (see below). The inclusion of grave goods made from raw materials exotic for the region (the $\mathrm{V}$ shaped jet button, Whitby; the Kimmeridge shale pulley ring, Dorset), indicates access to an extended network to obtain materials, although the burial assemblage contained a flint dagger, not a metal one. Can this burial be interpreted as a non-Beaker identity in existence at this time? Were the Beaker pot and metal artefacts deliberately excluded from the funerary representation of this individual, as they referred to a different identity? Healey (2012) makes a similar suggestion for the continued mining of flint, and rejection of metal and Beaker pottery at Grimes Graves, representing the continuation of traditional ways in face of new materials and items during the Beaker period by a native population.

There are parallels with other flint dagger burials in Britain. The date of flint daggers found in Beaker period funerary contexts is grouped to between 2250-2000BC when associated with radiocarbon dates, although Hilted Scandinavian daggers are later from 1950BC (Friemann 2014). These earlier flint daggers are most commonly found in inhumation burials without Beaker pottery in adult male graves (only seventeen of forty three burials listed by Friemann 2014 contained a Beaker pot as well). Although flint daggers are frequently described as part of the Beaker package, they are never found alongside metal objects in funerary contexts and of the seventeen recorded in funerary contexts associated with a Beaker pot, these were all found with Long Necked Beakers (Friemann 2014, 49), a type dated to 2200-2000BC (Needham 2012). 
In the Beaker Instituted phase (2250-1950BC) there is a distinct burial package that includes flint daggers, precludes metals, that sometimes incorporates other artefacts such as pulley rings, cushion stones and sponge fingers, but significantly in the majority of cases does not include a Beaker pot. Does the Durrington Walls sarsen burial define a different identity just after the fission horizon, one that is different to the Beaker identity, although both are defined through their funerary assemblages? The sarsen burial demonstrates that prestige items were not only restricted to Beaker burials; they were obtainable to individuals/groups who practised different burial traditions.

\section{Beaker period burials on the West Kennet Avenue, Avebury}

In 1934-5 and 1939 Alexander Keiller and Stuart Piggott excavated and restored the northern third of the West Kennet Avenue at Avebury (Smith 1965). The avenue consists of pairs of sarsen stones stretching over $2.4 \mathrm{~km}$ from the Avebury Henge, probably through to the Sanctuary at Overton Hill, which also contains a Beaker burial (Cunnington 1931), with construction of the West Kennet Avenue broadly dated to the period c. 25002300 BC (Gillings et al. 2008). Keiller's excavations uncovered four stones with associated inhumations on the West Kennet Avenue, as detailed by Smith (1965) (Table 1; Figure 4). Owing to space constraints only some of these burials will be discussed.

\section{Inhumation by stone hole $18 b$}

Keiller excavated stone hole 18b, knowing that Maud Cunnington (Cunnington 1913) had previously identified a buried sarsen stone at this location. The burial of stone $18 \mathrm{~b}$ had partially destroyed the stone hole and a grave associated with it, but enough survived to clarify the position of the stone hole, its original dimensions and the grave cut. The grave was separated from the stone hole by a wall of chalk $0.12 \mathrm{~m}$ wide, preventing a direct stratigraphic association, with an oval grave cut, $0.9 \mathrm{~m}$ long and $0.6 \mathrm{~m}$ wide (Smith 1965 , 209). The contents of the grave were disturbed by the burying of the sarsen stone, with some of the bones from the burial found in the pit beside the stone. The remains of the burial lacked any grave goods, and no radiocarbon date is available, although the form of the grave and suggested date of construction of the West Kennet Avenue suggests a Beaker period date. Keiller comments on the lack of grave goods: 'A curious feature of 
this burial consisted in the total absence of pottery of any description and it must be concluded in this case that no grave goods were buried with the corpse, unless, of course a vessel was discovered intact a farmer may have taken the "rude urn" as a souvenir of his operation.' (Keiller Archive, Keiller museum).

\section{Inhumation by stone hole $22 b$}

This undisturbed burial was found to the east of stone hole $22 \mathrm{~b}$, although no buried sarsen stone was found. Before the sarsen was removed it had fallen, forcing a large packing stone onto the grave protecting it. The grave was oval, with vertical sides, and a flat base being $1.38 \mathrm{~m}$ by $1.24 \mathrm{~m}$. The body was in a crouched position with its feet to the east and head to the west. The body had been placed on its back, head turned to the right and sloping slightly towards its shoulder, with the legs of the burial bent at the hips and the knees drawn up. Behind the shoulders a carinated bowl had been placed (Figure 5).

The pottery vessel from this grave is unique, having variously been described as 'an unusual carinated bowl' (Pollard and Reynolds, 2010, 129) and 'a decorated bowl of uncertain affinity' (Thomas, 1999 pp 219). The vessel is a flat bottomed bowl with a simple rim, with lower part decorated with incised triangle patterns (Figure 6). The style of the vessel strongly suggests a hybrid bowl fusing elements of Grooved Ware and Beaker pottery styles. The technique and the fabric match those used in Grooved Ware, yet the morphology of the vessel is more similar to Beaker pottery. It is a darker colour more similar to Grooved Ware pots, with circular decoration similar to Beaker styles, and incised triangles. Smith $(1965,229)$ suggests the pot as an 'interaction between RinyoClacton (Grooved Ware) and Beaker traditions'. Cleal and Pollard (2012) describe it as combining motifs from both Grooved Ware and Beaker traditions and was probably dated to the earliest period of Beaker use in the Avebury landscape. Does this hybrid Grooved Ware/Beaker pot represent an early fusion of Beaker and Grooved Ware identities, expressed in the fabric of the monument of the West Kennet Avenue, a symbolic joining of two distinct identities within the Avebury landscape? 


\section{Inhumation by stone hole $25 b$}

The remains of several individuals were found at the base of the stone hole $25 \mathrm{~b}$ and in the filling of the stone burial pit, with much of the burial having been destroyed by the digging of the pit to bury the stone. The remains of the body found in the stone hole were interpreted as being placed in an extension of the stone hole, after the erection of the stone. The grave and stone hole were recorded as being filled with the same packing material, suggesting some degree of contemporaneity. Within the stone burial pit Beaker pottery and more human bone were found, with two adolescents and one adult represented (Smith 1965, 209 -210). Keiller in his notes records 'a remarkable quantity of ox bones' (Keiller Archive, Keiller Museum).

\section{West Kennet burials summary}

These three burials from the West Kennet Avenue demonstrate a range of burial traditions present in the Avebury landscape during the Beaker period. Some are not associated with grave goods, some are associated with Beaker pottery, but interestingly one is associated with pottery that apparently fuses elements of Beaker and Grooved Ware pottery together. In terms of different identities, do these burials along the West Kennet Avenue represent individuals who belonged to different social groups, who co-existed within this monumental landscape? Is the interaction and possible joining of these groups expressed through the half Grooved Ware, half Beaker pot found in a burial on the West Kennet Avenue? Here is a monument, constructed around the time of the insertion of the Beaker set into Britain, which contains inhumations associated with Beaker material culture, inhumations with apparently no material culture and one inhumation containing a pot representing both Beaker and Grooved Ware characteristics. Maybe the West Kennet Avenue, joined to the Avebury Henge, was a physical manifestation of the wider world that these henge users were experiencing and symbolically represents the joining of more than one world view.

\section{Racton Man, Chichester, West Sussex}

This burial is located close to Westbourne in Sussex and was excavated in 1989, after an initial chance find by a metal detectorist. The site was subsequently excavated identifying 
an in-situ crouched inhumation burial of an adult male on his left hand side, orientated Man. The body was placed on the old land surface, potentially covered by a small mound of chalk rubble which had since been largely ploughed away. The circumstances of the discovery of the burial and its post excavation analysis are detailed by Needham (2017).

The individual was buried with a bronze dagger, a type considered to be transitional between types 1 and 2, labelled by Needham as type 1c (Needham et al. 2017, 87). A radiocarbon date on bone from the inhumation provided a date of $2455-2145 \mathrm{cal}$ BC (2 sigma, SUERC-55526; Needham et al. 2017, 103), firmly at or just after the fission horizon. There was no Beaker pot placed in the grave assemblage, although the individual clearly had access to elite or rare material objects, in this case a very early bronze dagger.

A number of other dagger burials have been excavated in southern England across the Beaker period. An example is the Milston barrow (Wiltshire) where a dagger was found with a primary crouched inhumation with its head to the northwest, but no Beaker pot was present (Colt Hoare, 1812, 185). Gerloff (1975) describes the Milston example as a flat riveted blade, now recognised as a series 2 dagger, which has been demonstrated to be present from 2100-2000BC, in Needham's (2005) revised chronology. Another example is barrow 3, Barrow Hills (Oxfordshire), which contained an inhumation with a 3 riveted bronze dagger, and again lacks any further grave goods in the burial assemblage. It has a radiocarbon date reported of 2500-1950 cal BC (2 sigma, OxA4355; Barclay and Halpin 1999, 152-153). Racton man is an example of a repeating pattern of burial rite, in the 'Beaker instituted phase', with an early bronze dagger accompanying a single inhumation.

This form of burial is recognised by Wilkin (2011) and also by Needham et al. (2017) who term them dagger burials, and they demonstrate a distinct post-fission burial rite, lacking Beaker pottery. The significance of this repeating pattern of burial can be interpreted as a statement of identity that is distinct to the Beaker identity, due to the exclusion of Beaker pottery (and other Beaker related artefacts) from the grave assemblage. In addition, daggers are not always associated with inhumation, such as the cremation dagger burial at barrow 4, Barrow Hills (Oxfordshire) (Barclay and Halpin 1999, 156). Like the case for the flint daggers, early bronze daggers are not objects exclusive to the Beaker using groups in Britain. Rather, a range of prestige goods are in circulation during this Beaker instituted phase (2250-1950BC). Of these, bronze daggers 
are sometimes included in burials, some of these burials contain individuals interred with Beaker Pots, whilst other burials contain individuals who also have access to prestige goods (bronze), but who are buried without other Beaker material culture in the grave assemblage.

\section{Discussion}

The examples presented here describe different burial traditions that are present during the Beaker period in southern England. However, do these different burial traditions represent different belief systems or identities? This debate hinges on whether the Beaker set, and in particular Beaker pottery, represents an identity and whether the interpretation of Beaker pottery within a grave is a cultural identifier that describes alignment with a wider concept of the Beaker world. If this stance is accepted, then the lack of a Beaker vessel in a burial is significant; it indicates alternative belief systems or identities, separate to, but co-existing with the Beaker identity.

It is also worth emphasising at this point, just what the Beaker set consists of, in terms of interpreting burial patterns as representing different identities. During the Beaker as exclusive culture phase, the artefact assemblage of barbed and tanged arrowheads, Beaker pottery, archers wrist guards and gold hair ties, deposited within grave assemblages, is an imported practice from northern Europe (Needham 2005). However, post the fission horizon at 2250BC, some artefact types are found within both Beaker and non-Beaker graves, such as jet buttons, flint daggers, sponge fingers, pulley rings and bronze daggers. It is then, questionable, whether such artefacts, post the fission horizon, are part of a Beaker set, and would be better described as a range of artefacts in circulation during this time period, available to both Beaker and non-Beaker related burial identities.

However, what these non-Beaker identities represent is a more difficult question to address. Is there a diverse prehistoric landscape in this period that contains different groups of people, some of which are Beaker using and others who are not? Or does the evidence suggest that within a group there was a diversity of social identities, one of which was Beaker associated? Which of course directly questions the archaeological interpretations of what Beaker material culture is? This question has to be at least partly addressed through a chronological perspective, as per Needham's (2005) model. There 
is not a fixed reference of 'Beakerness', with the types and forms of Beaker associated Beaker as exclusive culture phase, Beaker burials in Britain are primarily formed from individuals with ancestry from the 'continental Beaker complex', with relatively low numbers of indigenous individuals being represented. This pattern continues throughout the Beaker period and although the indigenous DNA contribution from the British Neolithic population does rise over the Beaker period, it remains a small component overall (with the caveat that only thirty seven British Beaker period individuals were analysed and some of these came from graves not containing a Beaker; Olalde et al. 2018).

In the early Beaker as circumscribed exclusive phase there would have been multiple social identities, as Beaker using individuals must have inserted themselves into a pre-existing social landscape. This pioneering horizon (or circumscribed exclusive phase) must have had at least two distinct identities co-existing to some degree in Britain, the Beaker identity and another, in the example of the West Kennet Avenue a society using Grooved Ware and associated with henges. Is this coexistence of different identities visible and being symbolically expressed through the addition of burials in different styles along the West Kennet Avenue? During this time it is possible to consider, at least initially, a prehistoric social landscape outside of the Beaker identity, as the archaeological record of the 'other' already archaeologically pre-exists, represented by the large monuments in southern England such as henges.

Post the fission horizon, Needham (2005) describes a diversification of burial styles, during the Beaker instituted phase, and Fokkens (2008) more generally discusses regional adaptions to the European wide Beaker phenomena. Multiple burial styles are evident both associated with, and not associated with, Beaker material culture. With Beaker associated burials there are changes in Beaker pottery styles, such as the development of Long Necked Beakers, and also new types of objects being placed in grave assemblages. However, often inhumations are not associated with Beaker pottery. The metal dagger burials are an example of this, and another is presented by the flint dagger burials, exemplified by the sarsen burial at Durrington Walls. Furthermore, Colt Hoare and Cunnington (Colt Hoare 1812) record numerous burials without a Beaker, just primary internments of individual skeletons, sometimes associated with antler (c. 20 primary inhumations associated with antler have been recorded; Carey and Edwards forthcoming). 
The excavations at Barrow Hills, (Oxfordshire), produced a range of burials that long time periods) that do not contain Beaker pottery such as barrow 12 with a central inhumation (grave 607) containing a flint flake and a bronze awl dated to 2350-1950 cal BC (2 sigma, BM-2699; Barclay and Halpin 1999, 99); the afore mentioned barrow 3 dagger burial; and possibly graves 4969, barrow 17 pit 1 and barrow 15 pit 1 (Barclay and Halpin 1999). In addition, at Barrow Hills (Oxfordshire), were a range of burials associated with Beaker pottery, some inhumations without grave goods, some inhumations without pottery but containing grave goods, and some inhumations associated with Food Vessels. Needham (2012) sees the use of Food Vessels as being 'a reaction from the rump of society'. However, possibly they are the development of one of a number of different identities being expressed through variation in burial rite during the Beaker period, but different to the Beaker identity. Barclay and Halpin (1999, chapter 9) highlight this variability at Barrow Hills, referring to non-Beaker funerary traditions, in a landscape with Beaker burials.

The often referred to Stonehenge Beaker burial does not have a Beaker pot (Evans 1983), but contains three barbed and tanged arrowheads, an archers brace, three pieces of bluestone and two lumps of grooved chalk; the barbed and tanged arrowheads of the individual appear to have been acquired very late in the life of the individual before they pierced his skin! Field and McOmish $(2016,118)$ refer to the Stonehenge 'Beaker burial' as a possible miscreant. However, the only part of the Beaker culture set associated with this inhumation is a stone wrist guard. Therefore, rather than representing someone who subscribed to a Beaker identity, does this Stonehenge inhumation represent an individual who was not Beaker, but had access to some of the material goods in circulation during this period? The companion burial represents another interesting example, who is related to the Amesbury Archer, is buried close to him, but yet does not have a Beaker in the grave assemblage, which is in conspicuous contrast to the Amesbury Archer (Fitzpatrick 2013).

A further set of examples include the non-Beaker burials at Fordington Farm, Dorset (Bellamy 1991), with the unaccompanied primary inhumations in graves 59 (2347-2039 cal BC 2 sigma; UB-3305) and 70 (2290-190 cal BC 2 sigma; UB-3304). Grave 61 (unphased) contained an inhumation with a barbed and tanged arrowhead in the pelvic region. The deceased had their head on a cattle scapulae and their feet placed on 
the axis vertebrae of the same species; behind the lower legs were two pieces of cattle 2201 cal BC (2 sigma; UB-6609). The other inhumation within this group, grave 74, containing an adult male and very small or premature infant, could also date to the period 2250-1950BC, although the stratigraphic relationship was unclear during excavation (Bellamy 1991). However, all the dated examples within this barrow group fall within the Beaker instituted phase, with the possibility of grave 61 pre-dating the fission horizon.

Other more recently excavated examples of unaccompanied inhumations include a burial at Ridgeway Farm, Purton, Wiltshire, with grave 9118 containing the crouched inhumation of a possible male aged 11-13. The body was placed on its right hand side, on a north south axis, with the head to the south, which is opposite to the general body position (although much of the skull was missing through truncation) and was dated to between 2290-2030 cal BC (SUERC-56574; Powell 2017). Grave 4231 outside Little Woodbury Salisbury, contained the redeposited or disturbed remains of at least two individuals, again lacking any form of grave goods. Two groups of bones were separated in the grave, one to the south end of the grave and the other in the centre. Two radiocarbon dates from the two individuals gives date ranges of 2200-1970 cal BC (2 sigma; SUERC47738) and 2130-1900 cal BC (2 sigma; SUERC-41685) (Powell 2015). These examples demonstrate that unaccompanied inhumation, both individually and in multiple occurred during the Beaker as instituted culture phase. Cleal (2005) also lists some non-Beaker associated inhumations in the Avebury landscape, including a possible Beaker period flat grave cemetery at Overton Down, with many inhumations not containing grave goods.

It is necessary to question what Beaker material culture actually is, within the Beaker instituted phase. A range of artefacts are in circulation during the Beaker period from $c$. 2250BC onwards; however, artefacts such as jet buttons, early bronze daggers and flint daggers are not exclusive to Beaker exchange networks or Beaker burials. Secondly, as the data from West Kennet Avenue and the Durrington Walls sarsen burial show, although funerary practices and construction of identities might have been exclusive, the landscapes these people were buried within were not. These landscapes were accessed by people who subscribed to different burial styles and by extrapolation were constructing different identities. Cleal and Pollard (2012) hint at this association between the interaction of Beaker and non-Beaker societies, indicating that cultural practices did not drastically change in the Wessex ceremonial centres with the appearance 
of Beaker pottery and burials, indicating Beaker material culture was absorbed into continued throughout the Beaker period, did so by a population who asserted traditional ways and values against innovations (associated with the adoption of Beaker material culture).

So what do these non-Beaker burials actually tell us about the organisation of prehistoric society? Are we discussing groups of peoples (tribes?) or individuals within a Beaker using society? Fowler $(2013,168)$ relates variation in burial styles in northern England between 2200-1700BC to variation in power, identity and social division, although the synthesis of non-Beaker associated burials in southern England is far from complete and this requires redress. However, there is some evidence that can lead us to consider what the Beaker complex was, and how society reacted to it and with it. Some, regions have a much shorted currency of Beaker use, such as southwest Britain (Jones and Quinnell, 2006), whilst other regions have a much longer currency of Beaker use, e.g. Wessex. This indicates different regional or sub-regional responses to the incursion of a new idea or new customs, and a new ways of doing things. In some areas, these new ways seem to have had less appeal and have a short duration of use. In comparison in southern England, especially Wessex, the Beaker burial rite and Beaker pottery use has a much longer currency with a late phase (post 1950BC), possibly referencing an earlier ideal.

The excavation at Over, Cambridgeshire (Garrow et al. 2014) shows that Collared Urn use overlaps with individuals referencing an earlier Beaker burial, before Collared urns and cremations become the dominant burial rite. Is this interpretable as a change in identity (how the dead were treated) and possibly by extension, belief system of the group using this cemetery? As significantly, as well as burial styles changing and different regional reactions to Beakerness, individuals still continue to be buried with Beaker pots during the Beaker as instituted culture phase; the forms of Beaker pottery diversify, but they are still recognisable as Beakers. If the currency of being Beaker had become less during this phase, potentially due to a lower ability to access exchange networks, particularly metals (as argued by Wilkins, 2011), potentially people were demonstrating identity through deliberately non-referencing Beaker material culture. Whether this is represented by individuals within a group or by different groups is unclear, although the regional variation of Beaker burials during this period does indicate this is possibly by 
different groups. Conversely, if it is within group variation that is being expressed through these different burial styles, these identities are being constructed through removing the direct association with Beaker material culture from the grave, such as dagger burials. These burials could be a diversification or elaboration of the Beaker burial tradition (Needham et al. 2018), but if this does represent elaboration of the Beaker burial rite, it has removed a direct reference to a Beaker idea in the grave assemblage.

The more the burial record of the Beaker period is explored, the more evidence comes to light of multiple types of funerary practice that occur in repeating patterns across wider monumental landscapes in southern England, datable to the Beaker Instituted phase; metal dagger burials, flint dagger burials, burials with no grave goods, possibly antler burials and of course Beaker burials. Given the evidence presented, and this is only a small sample of the potential data available from the funerary record for this period, it is suggested that the chronological phases put forward by Needham are amended to include the diversity of non-Beaker related funerary traditions (Table 2). This diversity of funerary traditions in southern England poses some challenging questions. Simply, why is there such diversity of burial practice evident within the Beaker period? What does this diversity of funerary practice represent in terms of construction of identities during the Beaker period? Are the non-Beaker burials in southern England an equivalent of Food Vessel practices in the Beaker instituted phase, more commonly found in northern Britain? Is there a connection between earlier burials not associated with the Beaker set in the Beaker as exclusive culture phase, and later burial styles in the Beaker as instituted culture phase that also omit Beaker material culture from the grave assemblage?

\section{Conclusion}

This paper has presented an initial, and admittedly limited, interpretation of some select evidence of the Beaker period funerary record in southern England, in line with the chronological sequence put forward by Needham (2005). This interpretation is not only consistent with the excavated evidence, but also helps to explain some of the trends visible in the archaeological record of this period. There are numerous inhumations from the British Beaker period that have gone 'under the radar', both in dating programmes and also general discussions of this period, due to a lack of artefacts found during excavation. Likewise, other burials are assigned as Beaker, based on their artefactual 
compositions, although the burials themselves lack Beaker pottery. There is much to be

\section{Acknowledgements}

Many people have helped throughout this research. The staff at Devizes Museum have been a huge source of help throughout; thanks especially to David Dawson for his discussions around this subject. The staff at the Keiller museum at Avebury are also thanked for their help, as are the staff at the Ashmoleum Museum and Chichester Museum. Stuart Ladd is acknowledged for information on Beaker burials. Lastly thank you to Charlie Hay for asking obvious and insightful questions, and for discussing the 
project more generally. The SETRiF fund at the University of Brighton generously supported part of this project. The reviewers are also thanked for all their helpful comments and constructive comments that have helped to improve the original manuscript.

\section{Bibliography}

Allen, M. J., Gardiner, J. \& Sheridan, A. (eds) 2012. Is there a British Chalcolithic? People, place and society in the late $3^{\text {rd }}$ millennium. Prehistoric Society Research paper 4. Oxbow: Oxford

Andrews, P. and Thompson, S. 2016. An early Beaker funerary monument at Porton Down, Wiltshire. Wiltshire Archaeological and Natural History Magazine, 109, pp. 38 $-82$.

Barclay, A. and Halpin, C. 1999. Excavations Barrow Hills, Radley, Oxfordshire: Volume I. The Neolithic and Bronze Age complex. Oxford University Committee for Archaeology: Oxford.

Barrowclough, D. 2010. Dating the Early Bronze Age in Northern England: Comparison with Ireland, Scotland and Wales. Red Dagger press: Cambridge. Bellamy, P. S. 1991. The excavation of Fordington Farm round barrow. Proceedings of the Dorset Natural History and Archaeology Society, 113, pp. 107 - 132.

Boast, R. 2002. Chapter 10 Pots as categories: British Beakers, in A Woodward and J D Hill (eds), Prehistoric Britain The Ceramic Basis, pp. 96- 105. Oxbow: Oxford Boast, R. 1995. Fine pots, pure pots, Beaker pots, in I Kinnes and G Varndell, (eds), Unbaked Urns of Rudely Shape. Essays on British and Irish pottery for Ian Longworth, pp. 69-79. Oxbow Books: Oxford.

Brodie, N. 1997. New perspectives on the Bell-Beaker culture. Oxford Journal of Archaeology, 16 (3), pp. 297 - 314.

Brück, J. 2004. Material metaphors. The relational construction of identity in Early Bronze Age burials in Ireland and Britain. Journal of Social Anthropology, 4 (3), pp. $307-333$.

Burgess, C. and Shennan, S. 1976. The Beaker phenomenon: some suggestions, in, C Burgess and R Miket, (eds), Settlement and Economy in the Third and Second Millennia BC. British Archaeological Reports British Series 33, pp. 309-31. BAR: Oxford. 
Case, H. 2004b. Beakers and the beaker culture, in, J Czebreszuk (ed), Similar but different. Bell Beakers in Europe, pp. 11 - 31. Sidestone Press: Leiden.

Case, H. 2004a. Beaker burial in Britain and Ireland. A role for the dead, in, M Besse and J Desideri (eds), Graves and funerary rituals during the late Neolithic and early Bronze Age in Europe (2700 - 2000BC), pp. 195 - 200. BAR: Oxford.

Case, H. 1995a. Chapter 6: Beakers: losing a stereotype, in I Kinnes and G Varndell, (eds), Unbaked Urns of Rudely Shape. Essays on British and Irish pottery for Ian Longworth, pp. 55-65. Oxbow Books: Oxford.

Case, H. 1995b. Some Wiltshire Beakers and their contexts. The Wiltshire Archaeological and Natural History Society Magazine, 88, pp. 1 - 17.

Carey, C. J and Edwards, C. Forthcoming. Antler burials in the Beaker period.

Childe, G. V. 1925. The dawn of European civilisation. Routledge and Keagan Paul ltd: London.

Clarke, D. L. 1970. Beaker Pottery of Great Britain and Ireland. Cambridge University Press: Cambridge.

Cleal, R. and Pollard, J. 2012. The revenge of the native: monuments, material culture, burial and other practices in the third quarter of the $3^{\text {rd }}$ millennium $\mathrm{BC}$ in Wessex, in, $\mathrm{M}$ Allen, J Gardiner and A Sheridan (eds), Is there a British Chalcolithic? People, place and polity in the later $3^{\text {rd }}$ millennium BC, pp. 317 - 332. Oxbow Books: Oxford.

Cleal, R. 2005. 'The small compass of the grave': early Bronze Age burial in and around Avebury and the Marlborough Downs, in, G Brown, D Field and D McOrmish (eds), The Avebury landscape. Aspects of the field archaeology of the Marlborough Downs, pp. 115, 132. Oxbow Books: Oxford.

Colt Hoare, R. 1812. Ancient Wiltshire. William Miller: London.

Colt Hoare, R. 1829. Tumuli Wiltunenses; a guide to the barrows on the plains of Stonehenge. J Rutter: Shaftesbury.

Cummings, V. 2017. The Neolithic of Britain and Ireland. Routledge: London. Cunnington, M. 1931. The Sanctuary on Overton Hill, near Avebury. Wiltshire Archaeological And Natural History Society Magazine, 45, pp. 300 - 335.

Cunnington, M. 1913. A buried stone in the Kennet Avenue. The Wiltshire Magazine, 38 , pp. $12-14$

Darvill, T. 2010. Prehistoric Britain. Routledge: Abingdon. 
Evans, J. G. 1983. Stonehenge - the environment in the late Neolithic and Early

Exon, S., Gaffney, V., Woodward, A. and Yorston, R. 2000. Stonehenge landscapes: journeys through real-and-imagined worlds. Archaeopress: Oxford.

Field, D. and McOrmish, D. 2016. Neolithic horizons. Monuments and changing communities in the Wessex landscape. Fonthill Media: London.

Fitzpatrick, A. P. 2017. The arrival of the Beaker set in Britain and Ireland, in, J T Koch and B Cunliffe, (eds), Celtic from the West 2. Oxbow Books: Oxford. Fitzpatrick, A. 2013. The Amesbury archer and the Boscombe Bowmen. Bell Beaker burials at Boscombe Down, Amesbury, Wiltshire. Wessex Archaeology: Salisbury. Fokkens, H. 2008. Background to Dutch Beakers: A critical review of the Dutch model, in, H Fokkens and F Nicolis (eds), Background to Beakers Inquiries into regional cultural backgrounds of the Bell Beaker complex. Sidestone Press: Leiden. Fowler, C. 2013. The emergent past. A relational realist archaeology of Early Bronze Age mortuary practices. Oxford University press: Oxford. Frieman, C. J. 2014. Double edged blades: re-visiting the British (and Irish) flint daggers. Proceedings of the Prehistoric Society, 80, pp. $33-65$.

Garrow, D., Meadows, J., Evans, C. and Tabor, J. 2014. Dating the dead: a high resolution radiocarbon chronology of burial within an early Bronze Age barrow cemetery at Over, Cambridgeshire. Proceedings of the Prehistoric Society, 80, pp. 207 $-236$.

Gerloff S. 1975. The Early Bronze Age daggers in Great Britain and a reconsideration of the Wessex culture. Beck: München.

Gibson, A. 2007. A Beaker veneer? Some evidence from the burial record, in, M Larsson and M Parker Pearson (eds), From Stonehenge to the Baltic Living with cultural diversity in the third millennium BC, pp. 47 -64. BAR: Oxford.

Gibson, 2004. Burials and Beakers: seeing beneath the Beaker veneer in Late Neolithic Britain, in, J Czebreszuk (ed), Similar but different. Bell beakers in Europe, pp. 11 31. Sidestone Press: Leiden.

Gibson, A. 2002. Prehistoric pottery. Tempus: Stroud. 
Gillings, M., Pollard, J., Wheatley, D. and Peterson, R. 2008. Landscape of the megaliths: excavation and fieldwork on the Avebury monuments $1997-2003$. Oxbow Books: Oxford.

Greenwell, W. 1877. British Barrows. A record of the examination of sepulchral mounds in various parts of England. Clarendon Press: Oxford.

Guerra-Doce, E. 2006. Exploring the significance of Beaker pottery through residue analysis. Oxford Journal of Archaeology, 25 (3), pp. 247-259.

Hamilton, S. 2002. Between ritual and routine: interpreting British prehistoric pottery production and distribution, in, A Woodward and J D Hill (eds), Prehistoric Britain The Ceramic Basis, pp. 38 - 53. Oxbow: Oxford.

Hawkes, C. and Hawkes, J. 1949. Prehistoric Britain. Penguin Books: London. Healey, F. 2012. Chronology, corpses, ceramics copper and lithics, in, M Allen, J Gardiner and A Sheridan (eds), Is there a British Chalcolithic? People, place and polity in the later $3^{\text {rd }}$ millennium BC, pp. 145 - 163. Oxbow Books: Oxford.

Higham, R. and Carey, C. 2019. The sarsen burial at Durrington Walls. Wiltshire Archaeological and Natural History Society Magazine, 112, pp. 74-84

Johnson, M. 2010. Archaeological theory (2 ${ }^{\text {nd }}$ edition). Wiley-Blackwell: Chichester. Jones, A. M., Brunning, R. and McKinley, J. I. 2017. Barrow 4 (G4), Milton Lilbourne, Wiltshire: new analysis and dating of the log coffin burial. Wiltshire Archaeological and Natural History Magazine, 110, pp. 123 - 133.

Jones, A. 2008. How the dead live, in, J Pollard (ed), Prehistoric Britain, pp. 177 201. Blackwell: Oxford.

Jones, A. and Quinnell, H. 2006. Cornish Beakers: new discoveries and perspectives. Cornish Archaeology, 45, pp. $31-69$.

Needham, S., Kenny, J., Cole, G., Montgomery, J., Jay, M., Davis, M. \& P. Marshall. 2017. Death by combat at the dawn of the Bronze Age? Profiling the daggeraccompanied burial from Racton, West Sussex. The Antiquaries Journal, 97, pp. 65 117.

Needham, S. 2016. The lost cultures of the Halberd bearers: a non-Beaker ideology in later $3^{\text {rd }}$ millennium Atlantic Europe, in, B Cunliffe and T Koch (eds), Celtic from the West 3. Atlantic Europe in the metal ages: questions of shared language. Oxbow Books: Oxford. 
Needham, S. 2012. Case and place for the British Chalcolithic, in, M Allen, J Gardiner

Needham, S. 2007. Isotopic aliens: Beaker movement and cultural transmissions, in, $M$ Larsson and M Parker Pearson, (eds), From Stonehenge to the Baltic Living with cultural diversity in the third millennium BC, pp. 41 - 46. BAR: Oxford.

Needham, S. 2005. Transforming Beaker culture in North-West Europe; processes of fusion and fission. Proceedings of the Prehistoric Society, 71, pp. 171- 217.

Parker Pearson, M., Chamberlain, A., Jay, M., Richards, M., Sheridan, A., Curtis, N., Evans, J., Gibson, A., Hutchison, M., Mahoney, P., Marshall, P., Montgomery, J., Needham, S., O'Mahoney, S., Pellegrini, M. and Wilkin, N. 2016. Beaker people in Britain: migration, mobility and diet. Antiquity, 90 (351), pp. 620 - 637.

Olalde, I., Brace, S., Allentoft, M. E., Armit, I., Kristiansen, K., Booth, T., Rohland, N., Mallick, S., Szécsényi-Nagy, A., Mittnik, A., Altena, E., Lipson, M., Lazaridis, I., Harper, T. K., Patterson, N., Broomandkhoshbacht, N., Diekmann, Y., Faltyskova, Z., Fernandes, D., Ferry, M., Harney, E., de Knijff, P., Michel, M., Oppenheimer, J., Stewardson, K., Barclay, A., Werner Alt, K., Liesau, C., Ríos, P., Blasco, C., Vega Miguel, J., Menduiña García, R., Avilés Fernández, A., Bánffy, E., Bernabò-Brea, M., Billoin, D., Bonsall, C., Bonsall, L., Allen, T., Büster, L., Carver, S., Castells Navarro, L., Craig, O. K., Cook, G. T., Cunliffe, B., Denaire, A., Egging Dinwiddy, K., Dodwell, N., Ernée, M., Evans, C., Kuchařík, M., Francès Farré, J., Fowler, C., Gazenbeek, M., Garrido Pena, R., Haber-Uriarte, M., Haduch, E., Hey, G., Jowett, N., Knowles, T., Massy, K., Pfrengle, S., Lefranc, P., Lemercier, O., Lefebvre, A., Heras Martínez, C., Galera Olmo, V., Bastida Ramírez, A., Lomba Maurandi, J., Majó, T., McKinley, J. I., McSweeney, K., Gusztáv Mende, B., Modi, A., Kulcsár, G., Kiss, V., Czene, A., Patay, R., Endrődi, A., Köhler, K., Hajdu, T., Szeniczey, T., Dani, J., Bernert, Z., Hoole, M., Cheronet, O., Keating, D., Velemínský, P., Dobeš, M., Candilio, F., Brown, F., Flores Fernández, R., Herrero-Corral, A., Tusa, S., Carnieri, E., Lentini, L., Valenti, A., Zanini, A., Waddington, C., Delibes, G., Guerra-Doce, E., Neil, B., Brittain, M., Luke, M., Mortimer, R., Desideri, J., Besse, M., Brücken, G., Furmanek, M., Hałuszko, A., Mackiewicz, M., Rapiński, A., Leach, S., Soriano, I., Lillios, K. T., Luís Cardoso, J., Parker Pearson, M., Włodarczak, P., Price, T. D., Prieto, P., Rey, P., Risch, R., Rojo Guerra, M. A., Schmitt, A., Serralongue, J., Maria Silva, A., Smrčka, V., Vergnaud, L., 
Zilhão, J., Caramelli, D., Higham, T., Thomas, M. G., Kennett, D. J., Fokkens, H., W., Barnes, I., Lalueza-Fox, C. and Reich, D. 2018. The Beaker phenomenon and the genomic transformation of northwest Europe. Nature, 555, pp. 190-196.

Owoc, M. A. 2000. Aspects of ceremonial burial in the Bronze age of south-west Britain. Unpublished $\mathrm{PhD}$ thesis, University of Sheffield.

Parker, Pearson, M., Sheridan, A. and Needham, S. 2013. Bronze Age tree-trunk coffin graves in Britain, in, N D Melton, J Montgomery and C J Knüsel (eds), Gristhorpe Man A life and death in the Bronze Age. Oxbow Books: Oxford.

Parker Pearson, M. 2012. Stonehenge: exploring the greatest stone age mystery. Simon and Schuster: London.

Patten, R. 2012. Trumpington Meadows, Cambridge, an archaeological excavation. Cambridge Archaeological Unit: Cambridge.

Peters, F. 2000. Two traditions of Bronze Age burial in the Stonehenge landscape. Oxford Journal of Archaeology, 19 (4), pp. 343 - 358.

Piggot, S. 1954. Neolithic cultures of the British Isles. Cambridge University Press: Cambridge.

Pollard, J. and Reynolds, A. 2010. Avebury the biography of a landscape. The History Press: Stroud.

Pollard, J. 2002. The nature of archaeological deposits and find assemblages, in A Woodward and J D Hill (eds), Prehistoric Britain The Ceramic Basis, pp. 22 - 33. Oxbow: Oxford.

Powell, A. B., Beach, S. and Leivers, M. 2018. Prehistoric deposition, burial and settlement on Salisbury Plain: archaeological investigations along the new military tracks, 2009-2012. Wiltshire Archaeological and Natural History Magazine, 111, pp. $84-193$.

Powell, A. B. 2017. An early Bronze Age burial, early to middle Iron Age settlement and Romano-British activity at Ridgeway Farm, Purton, Wiltshire. Wiltshire Archaeological and Natural History Magazine, 110, pp. 17 - 55.

Powell, A. B. 2015. Bronze Age and early Iron Age burial grounds and later landscape development outside Little Woodbury, Salisbury, Wiltshire. Wiltshire Archaeological and Natural History Magazine, 108, pp. $44-78$. 
Rowley-Conwy, P. 2004. The Three Age system in English: new translations of the

Shepherd, A. 2012. Stepping out together: men, women and their Beakers in time and space, in, M Allen, J Gardiner and A Sheridan (eds), Is there a British Chalcolithic? People, place and polity in the later $3^{\text {rd }}$ millennium BC, pp. 257 - 280. Oxbow Books: Oxford

Sherratt, A. 1991. Sacred and profane substances: the ritual use of narcotics in Later Neolithic Europe, in P Garwood, D Jennings, R Skeates and J Toms (eds), Scared and Profane. Proceedings of a conference on archaeology, ritual and religion, Oxford, 1989. Oxford University Committee for Archaeology, Monograph no. 32. Short Run Press: Exeter.

Sheridan, A. 2012. A Rumsfeld reality check: what we know, what we don't know, and what we don't know we don't know about the British Chalcolithic in Britain and Ireland, in, M Allen, J Gardiner and A Sheridan (eds), Is there a British Chalcolithic? People, place and polity in the later $3^{\text {rd }}$ millennium BC, pp. 40 - 55. Oxbow Books: Oxford Smith, I. F. 1965. Windmill Hill and Avebury. Excavations by Alexander Keiller 1925 - 1939. Clarendon Press: Oxford.

Šoberl, L. 2011. Pots for the afterlife: organic residue analysis of British Early Bronze Age pottery from funerary contexts. Unpublished $\mathrm{PhD}$ thesis, University of Bristol.

Thomas, J. 1999. Understanding the Neolithic (second edition). Routledge: London. Thomas, J. 1991. Reading the body: Beaker funerary practice in Britain, in, P Garwood, D Jennings, R Skeates and J Toms (eds), Scared and Profane. Proceedings of a conference on archaeology, ritual and religion, Oxford, 1989. Oxford University Committee for Archaeology, Monograph no. 32. Short Run Press: Exeter.

Van Linden, M. 2004. Polythetic networks, coherent people: A new historical hypothesis for the Bell Beaker Phenomenon, in, J Czebreszuk (ed), Similar but different. Bell beakers in Europe, pp. 35 - 62. Sidestone Press: Leiden

Wilkin, N. C. A. 2013. Food Vessel pottery from early Bronze Age funerary contexts in northern England: a typological contextual study. Unpublished PhD thesis, University of Birmingham. 
Wilkin, N. C. A. 2011. Grave-goods, contexts and interpretations: towards regional 37.

Woodward, A. and Hunter, J. 2015. Ritual in Early Bronze Age Grave Goods: An examination of ritual and dress equipment from Chalcolithic and Early Bronze Age graves in England. Oxbow Books: Oxford.

Figure 1: The locations of the case study burials.

Figure 2: The probable location of the sarsen burial from Durrington Walls. The location of the grave was not recorded by Colt Hoare, but its location has been suggested through the presence of sarsen stone, recorded in 1887 (see Higham and Carey 2019).

Figure 3: The grave goods from the sarsen burial, Durrington Walls, showing: left, the original engraving in Ancient Wiltshire (A) and; right, the grave goods of a flint dagger (B), Kimmeridge Shale pulley ring (C) sponge finger (D), a jet $\mathrm{V}$ button (E) and two chalk (flint) balls (F). (Images B - F used with permission from Devizes Museum). Figure 4: The location of the burials on the West Kennet Avenue, Avebury, Wiltshire. Figure 5: The excavation of the burial at stone hole 22b, on the West Kennet Avenue, Avebury showing: top, the position of the carinated bowl behind the shoulders in the grave and; bottom, the location of the grave relative to the stone hole. (Scans used with permission from Alexander Keiller Museum, Avebury).

Figure 6: The carinated bowl from the West Kennet Avenue burial, stone hole 22b.

Table 1: Excavated inhumations along the West Kennet Avenue.

Table 2: Revised interpretative sequence, building on Needham's (2005) suggested Beaker period phases.

\begin{tabular}{|l|l|l|l|}
\hline Stone & $\begin{array}{l}\text { Number of } \\
\text { inhumations }\end{array}$ & Grave goods & Other comments \\
\hline Stone 18b & 1 & None & \\
\hline Stone 22b & 1 & Ceramic Bowl & $\begin{array}{l}\text { Ceramic bowl, almost complete. } \\
\text { Possibly early in the Beaker } \\
\text { period, 2450-2250BC }\end{array}$ \\
\hline
\end{tabular}




\begin{tabular}{|l|l|ll|l|}
\hline Stone 25b & 3 & $\begin{array}{l}\text { Beaker, } \\
\text { skeleton }\end{array}$ & $\begin{array}{l}\text { Fragmentary vessel, notched } \\
\text { stamp decoration, burnished } \\
\text { reddish surface. Short necked } \\
\text { Beaker - possibly post 2300BC. } \\
\text { The Keiller archive records the } \\
\text { presence of ox bones in the } \\
\text { burial. }\end{array}$ \\
\hline Stone 29a & 1 & Beaker & $\begin{array}{l}\text { Low carinated Beaker, red } \\
\text { burnished surfaces and cord } \\
\text { impressed beneath the rim. } \\
\text { Likely to date to the early Beaker } \\
\text { as exclusive culture phase 2450 } \\
-2250 \mathrm{C}\end{array}$ \\
\hline
\end{tabular}

Table 1: Excavated inhumations along the West Kennet Avenue.

\begin{tabular}{|l|l|l|}
\hline Name & Date & Characteristics \\
\hline $\begin{array}{l}\text { Chalcolithic: } \\
\text { Beaker }\end{array}$ & $2450-$ & $\begin{array}{l}\text { Early pioneer groups associated with Beaker material } \\
\text { culture are present in the UK. Found within wider } \\
\text { native Later Neolithic social landscape. Strict rules } \\
\text { governing identity of the 'Beaker Culture', with a } \\
\text { limited artefact diversity. No 'native' Late Neolithic } \\
\text { burial tradition, thus Beaker inhumations dominate the } \\
\text { archaeological record. Relatively low diversity of } \\
\text { artefact types found within funerary assemblages, } \\
\text { including, Beaker pottery, barbed and tanged }\end{array}$ \\
\hline
\end{tabular}




\begin{tabular}{|l|l|l|}
\hline \multicolumn{2}{|l|}{} & \multicolumn{2}{|l|}{$\begin{array}{l}\text { arrowheads, gold hair ties, cushion stones and copper } \\
\text { knives }\end{array}$} \\
\hline $\begin{array}{l}\text { FISSION HORIZON } \\
\text { Identity Phase }- \\
\text { including } \\
\text { Beaker } \\
\text { diversification }\end{array}$ & $\begin{array}{l}2250- \\
\text { 1950BC }\end{array}$ & $\begin{array}{l}\text { Non-Beaker groups with different world views, adopt } \\
\text { inhumation in a range of styles. Beaker inhumations } \\
\text { continue and diversify. An increasingly diverse range } \\
\text { of artefacts types are visible in the archaeological } \\
\text { inhumation record, including antlers, jet buttons, shale } \\
\text { pulley rings, bronze daggers, flint daggers, whetstones } \\
\text { and strike a lights, with these artefact types available } \\
\text { to multiple social groups. Monumental landscapes } \\
\text { were available for inhumation of individuals from } \\
\text { multiple traditions. Development of other pottery } \\
\text { styles alongside Beaker such as Collared Urns and } \\
\text { Food Vessels. }\end{array}$ \\
\hline Early & $\begin{array}{l}\text { Bge } \\
1700 \mathrm{BC}\end{array}$ & $\begin{array}{l}\text { Multiple inhumation burial traditions continue, with } \\
\text { the emergence of Wessex style burials. A range of } \\
\text { pottery styles found in both inhumation and cremation } \\
\text { burials. Some Beaker burials still evident (especially } \\
\text { in Wessex), but the Beaker pottery is often poorly } \\
\text { made, and the Beaker burials are artefact poor, } \\
\text { possibly an archaic form. }\end{array}$ \\
\hline
\end{tabular}

Table 2: Revised interpretative sequence, building on Needham's (2005) suggested Beaker period phases. 


\section{Multiple identities in the Beaker period: interpreting inhumations out of the Beaker spotlight in southern England}




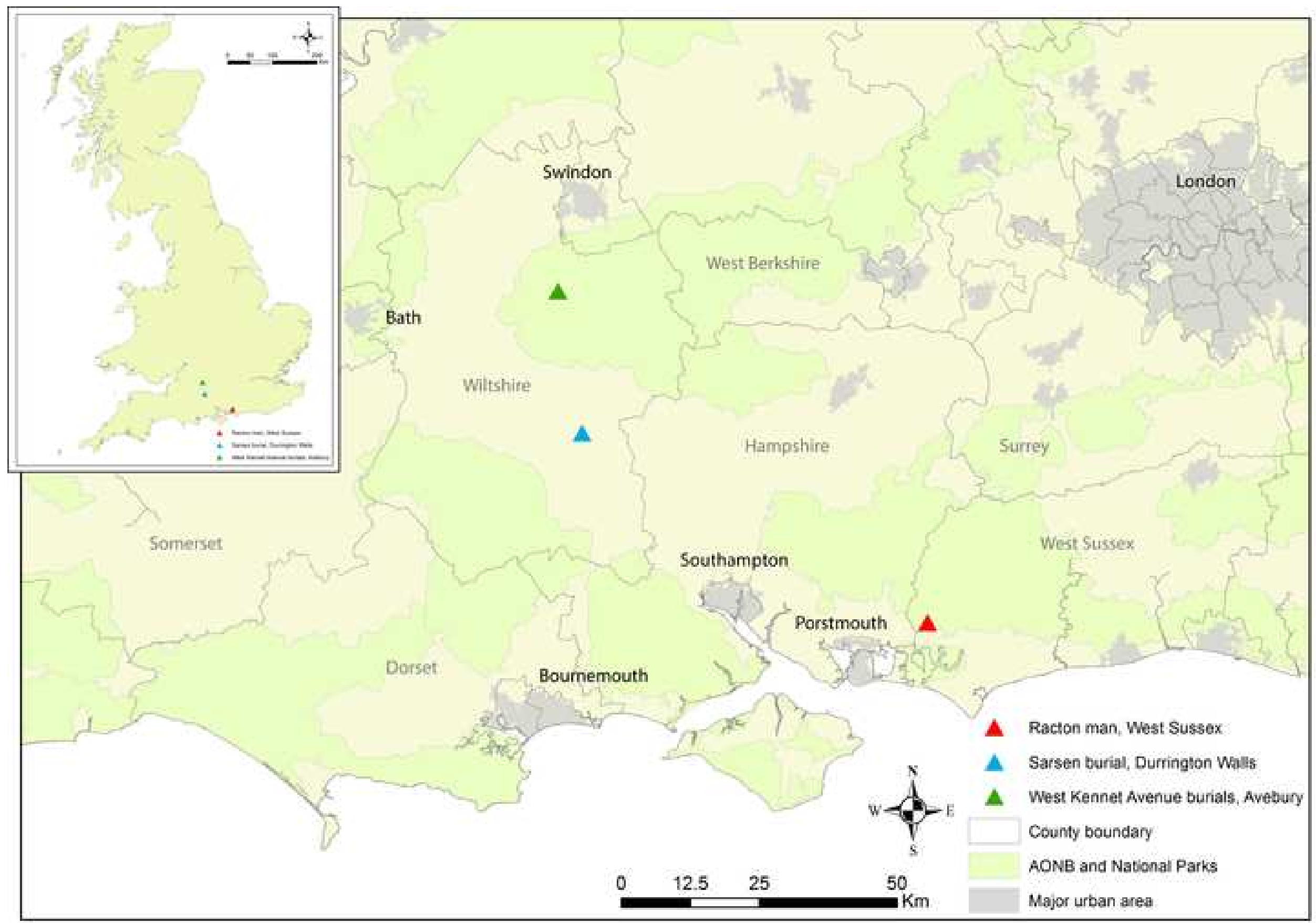




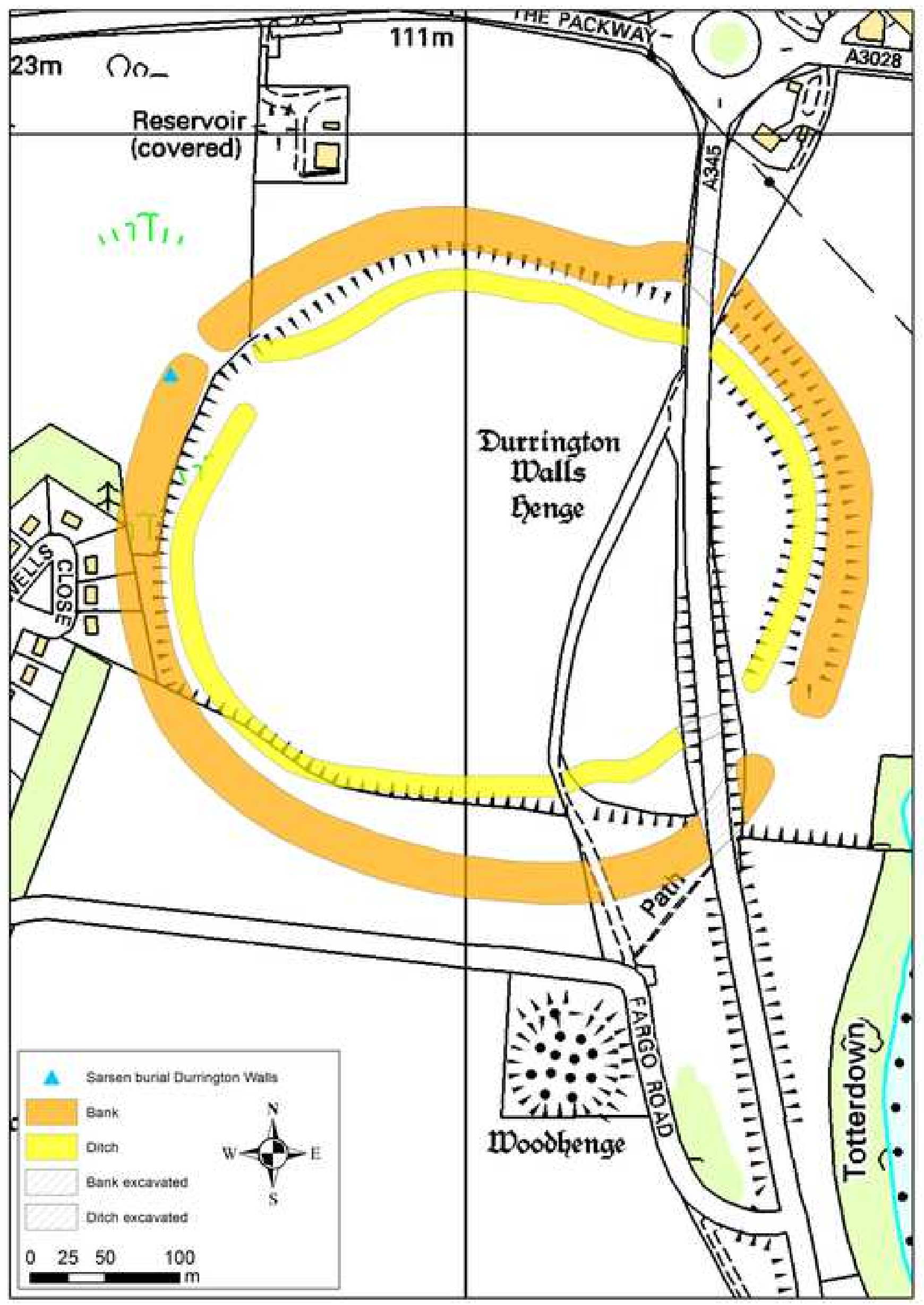


A

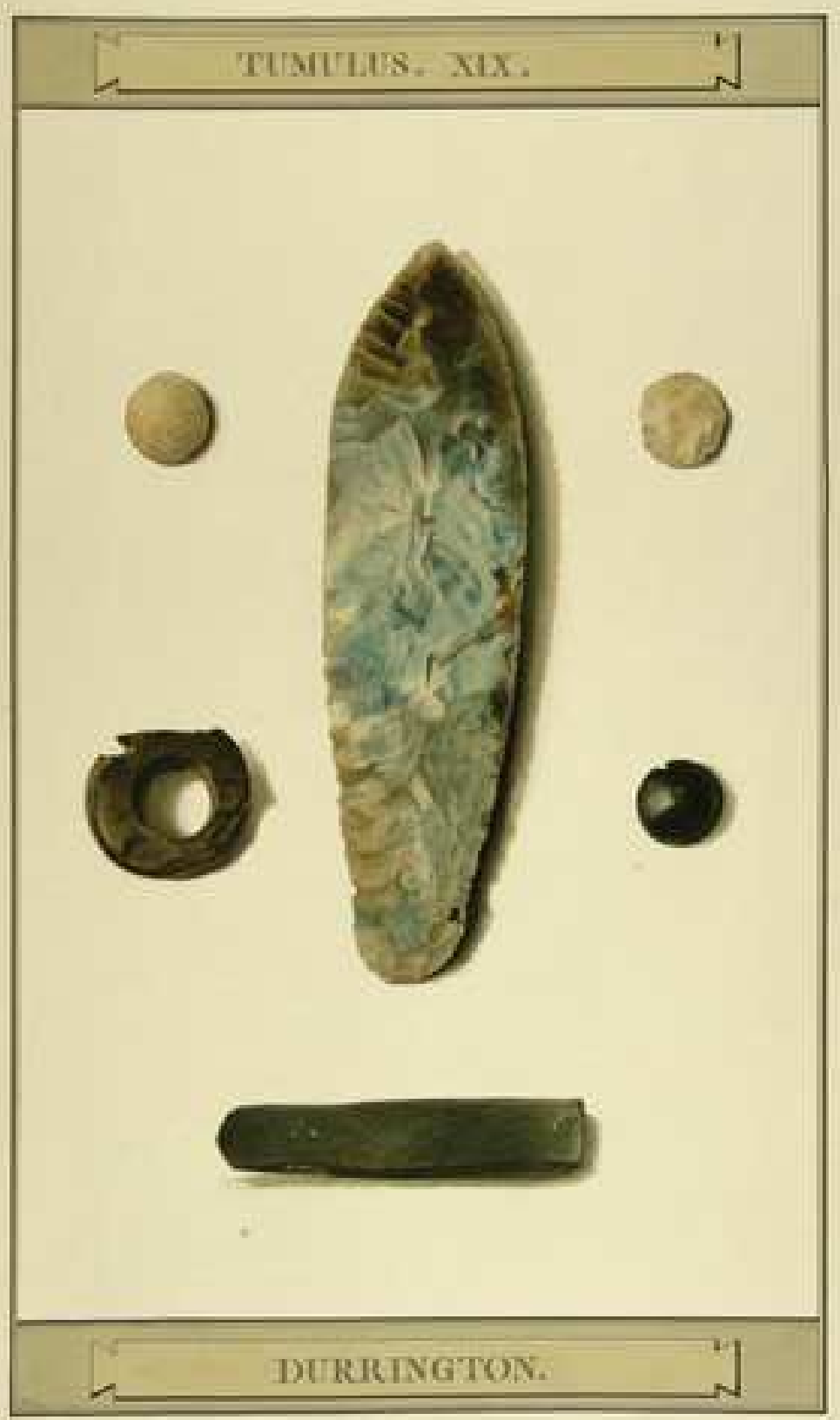

B

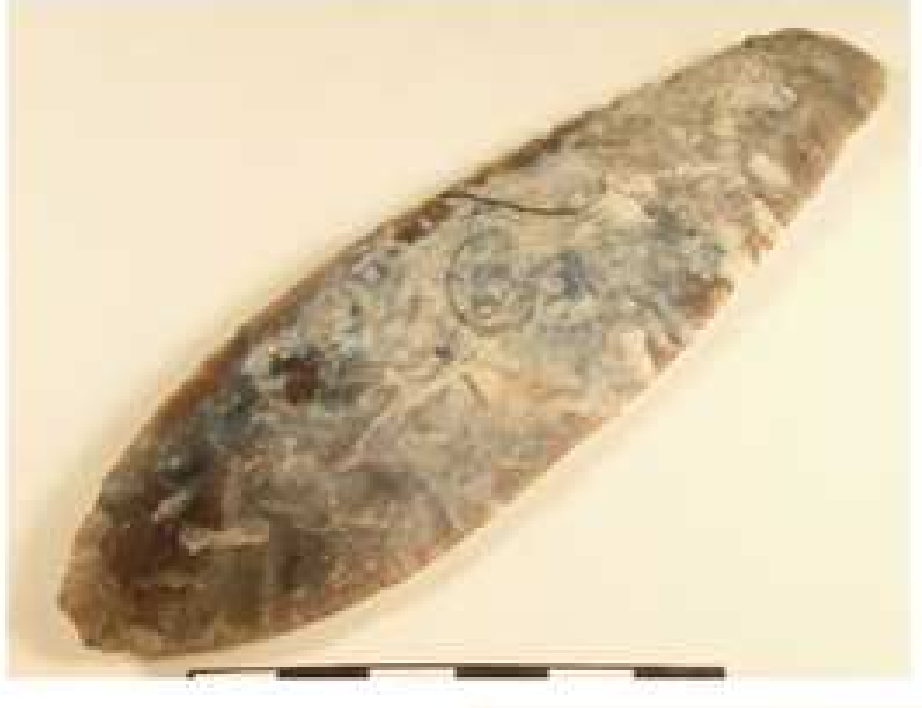

D
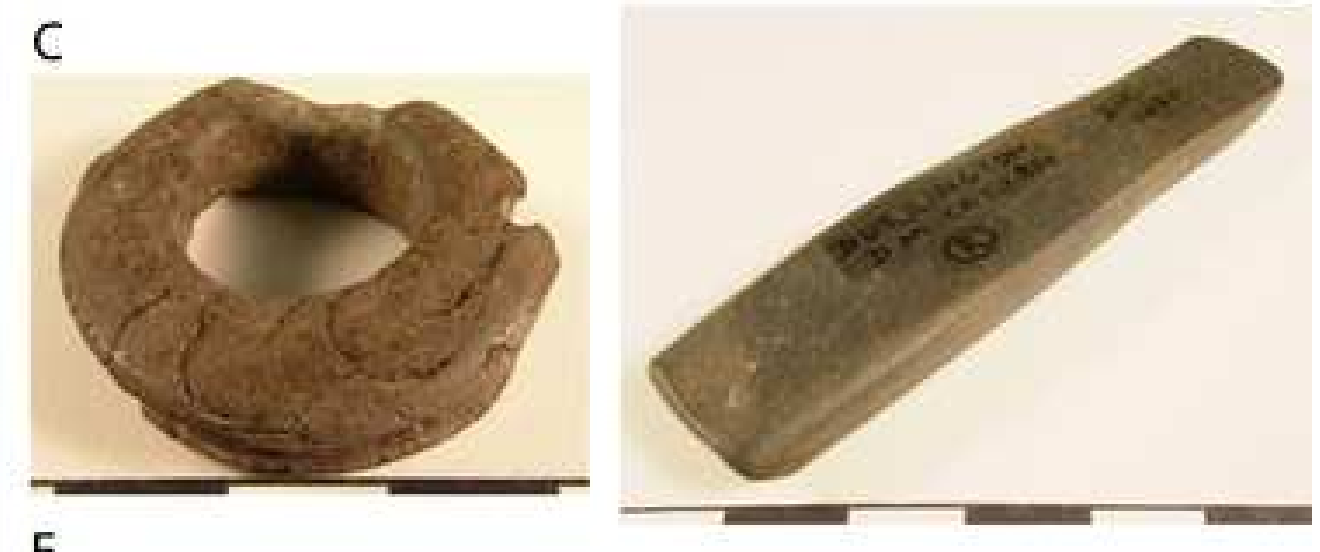

E

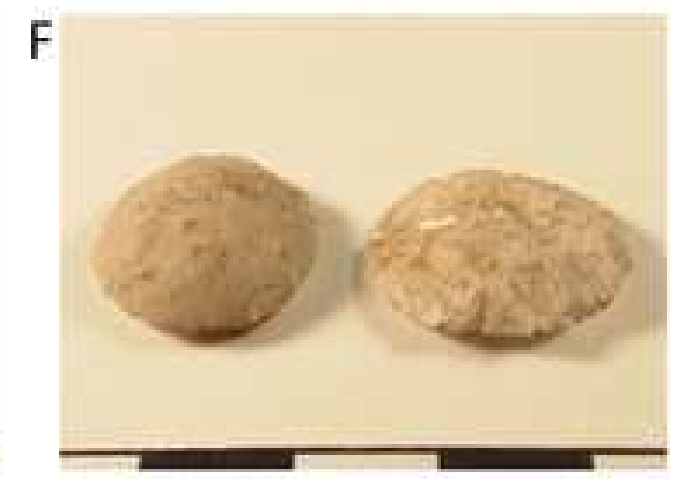




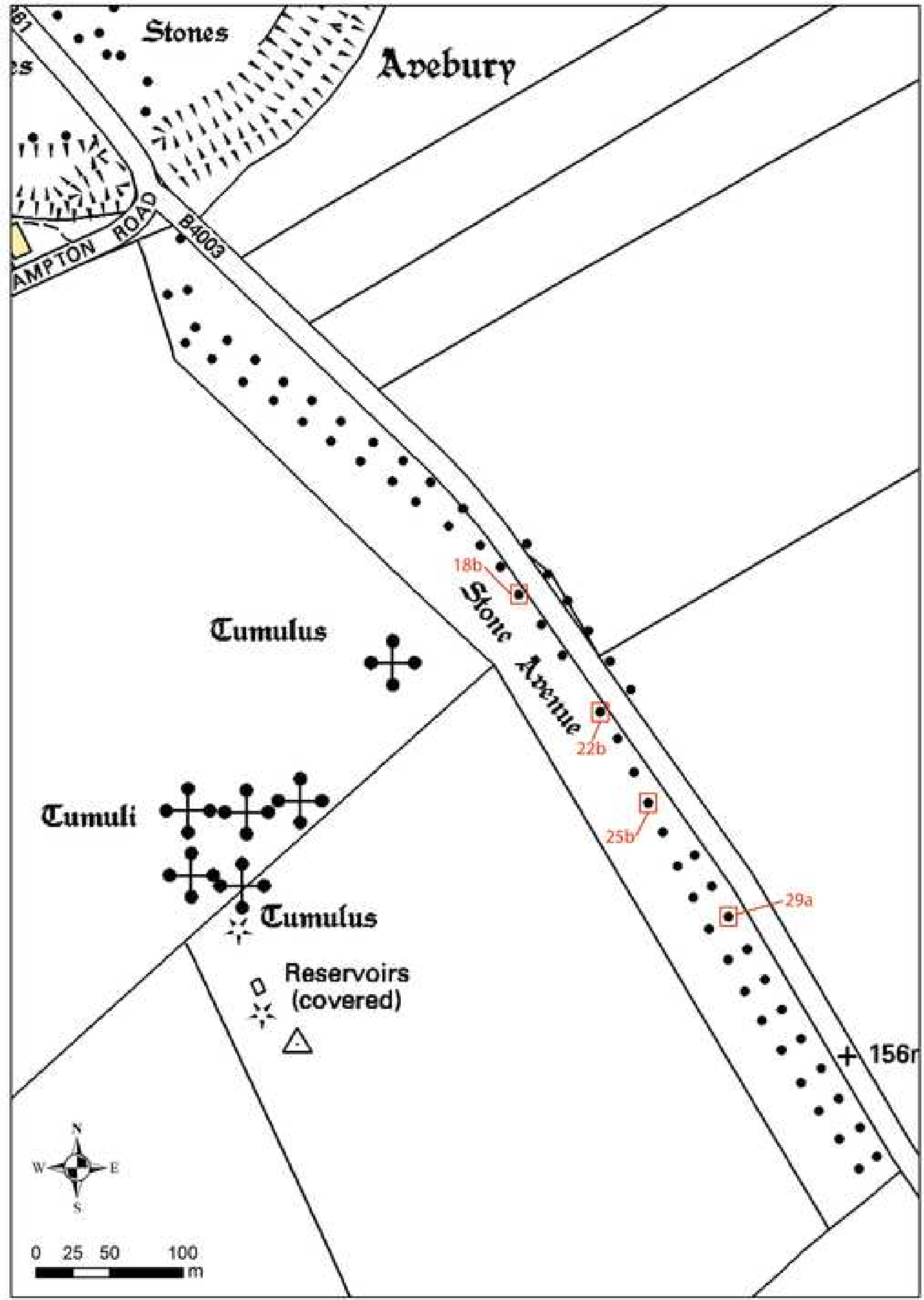




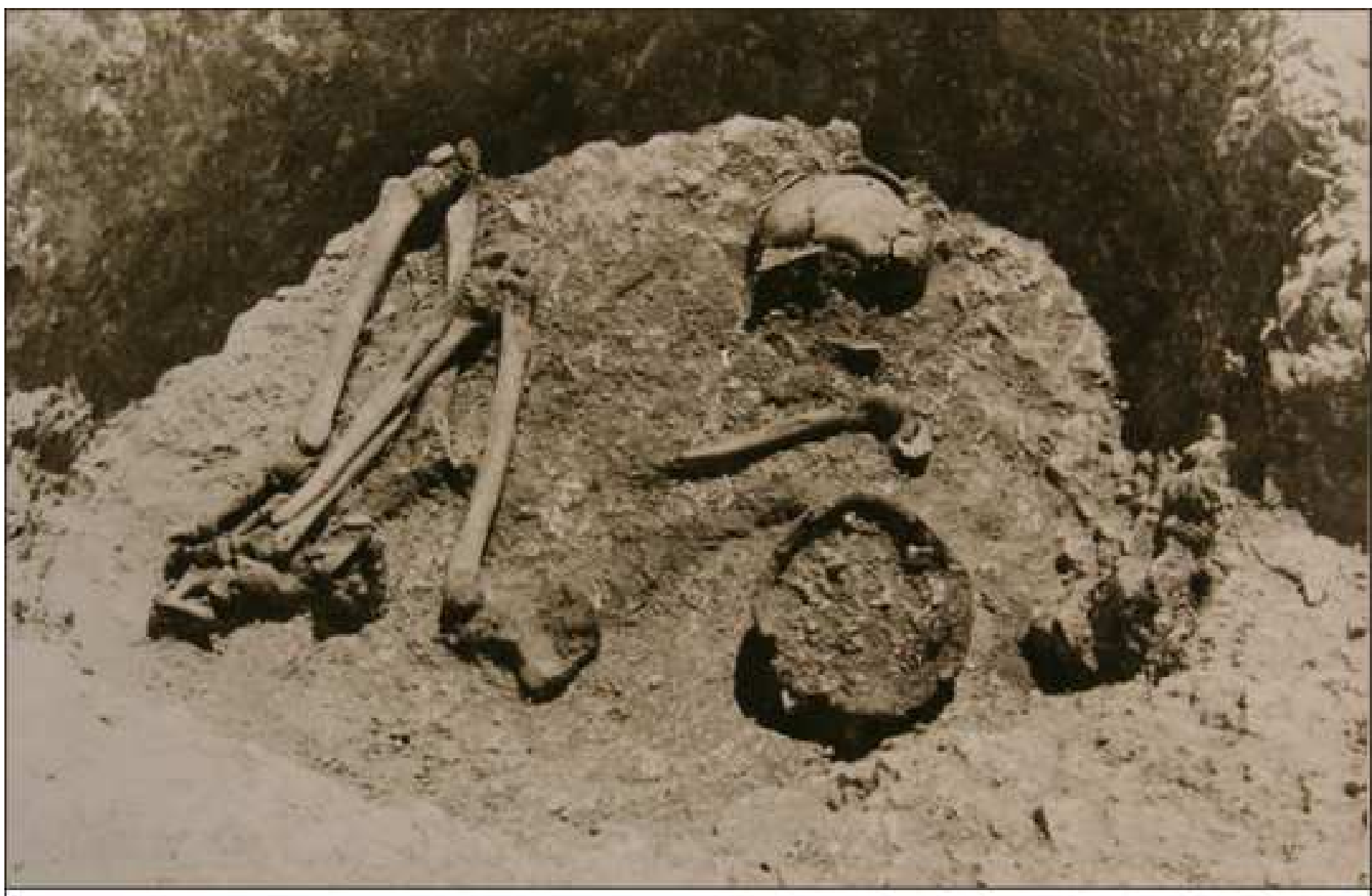

Ke

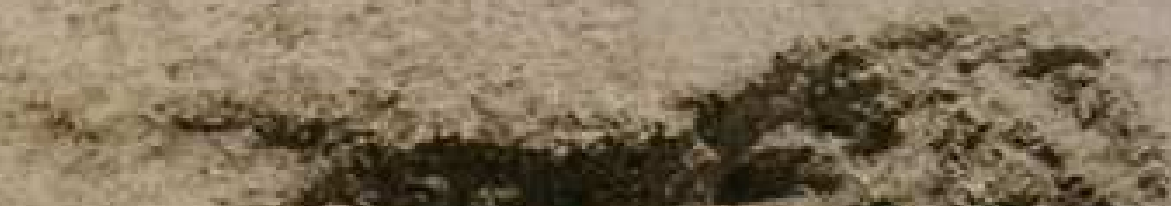

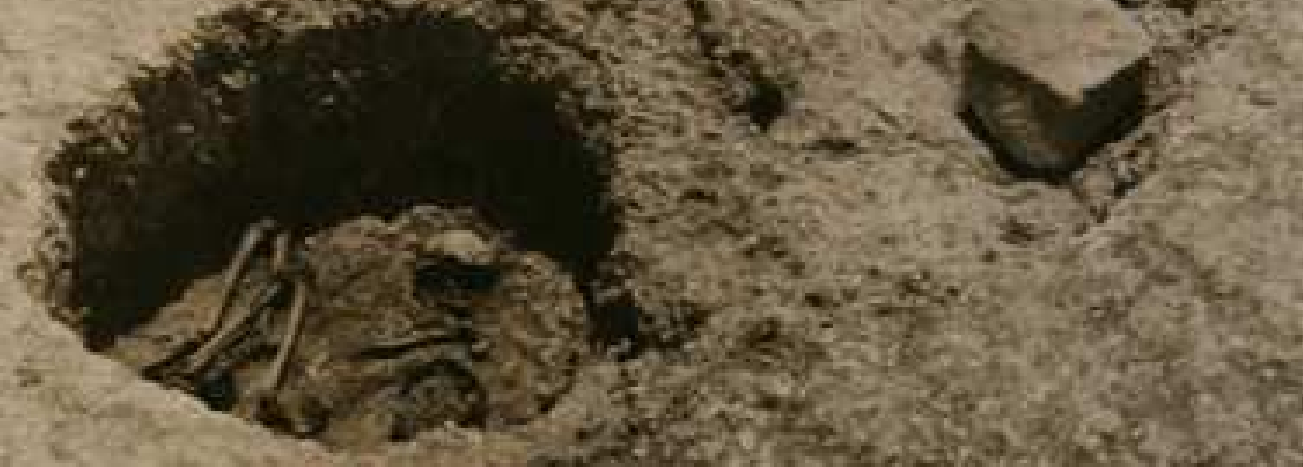

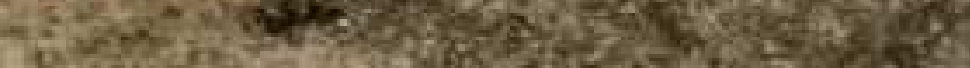

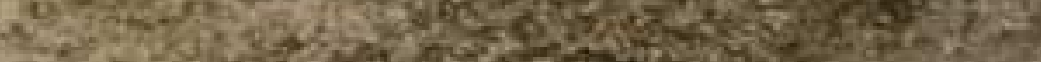

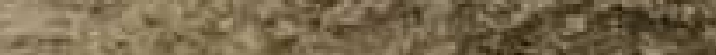



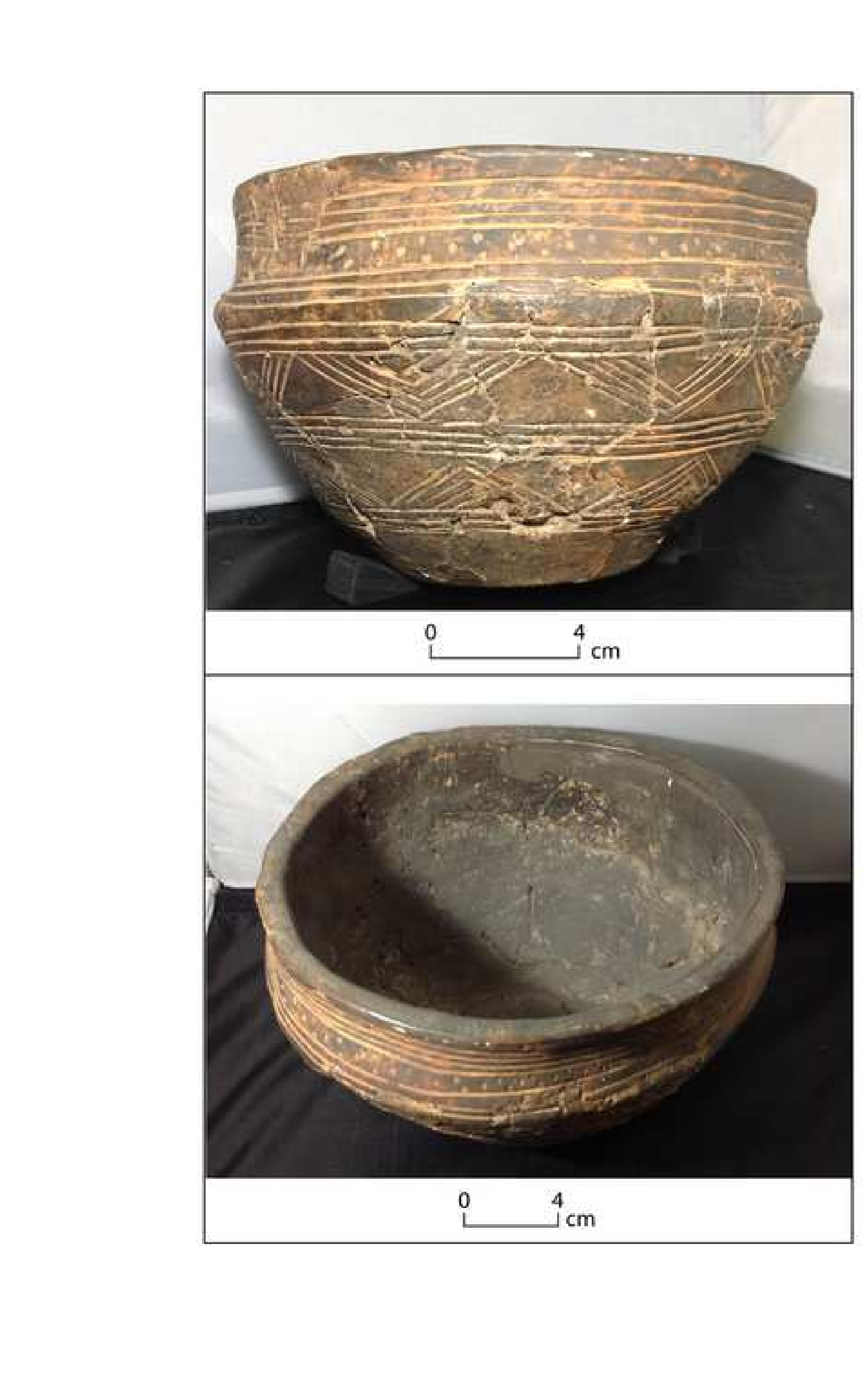

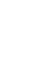

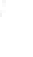
$\mathrm{cm}$ 